\title{
Silicon Chemistry in Fluorinated Chemical Vapor Deposition of Silicon Carbide
}

Pontus Stenberg, Pitsiri Sukkaew, Ildiko Farkas, Olof Kordina, Erik Janzén, Lars Ojamäe,
Örjan Danielsson and Henrik Pedersen

Journal Article

\section{Tweet}

N.B.: When citing this work, cite the original article.

Original Publication:

Pontus Stenberg, Pitsiri Sukkaew, Ildiko Farkas, Olof Kordina, Erik Janzén, Lars Ojamäe, Örjan Danielsson and Henrik Pedersen, Silicon Chemistry in Fluorinated Chemical Vapor Deposition of Silicon Carbide, The Journal of Physical Chemistry C, 2017. 121(5), pp.27112720.

http://dx.doi.org/10.1021/acs.jpcc.6b10849

Copyright: American Chemical Society

http://pubs.acs.org/

Postprint available at: Linköping University Electronic Press

http://urn.kb.se/resolve?urn=urn:nbn:se:liu:diva-134247

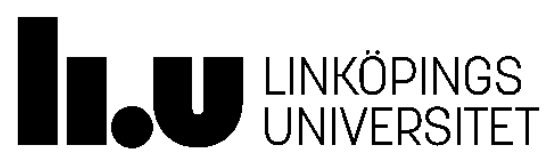




\section{Silicon Chemistry in Fluorinated Chemical Vapor Deposition of Silicon Carbide}

Pontus Stenberg, Pitsiri Sukkaew, Ildiko Farkas, Olof Kordina, Erik Janzén, Lars

Ojamäe, Örjan Danielsson, Henrik Pedersen*

Department of Physics, Chemistry and Biology, Linköping University, 58183 Linköping,

Sweden

*E-mail: henrik.pedersen@liu.se

\section{Abstract}

The use of chlorinated chemical vapor deposition (CVD) chemistry for growth of homoepitaxial layers of silicon carbide (SiC) has diminished the problem of homogenous gas phase nucleation, mainly the formation of Si droplets, in CVD of SiC by replacing Si-Si bonds with stronger $\mathrm{Si}-\mathrm{Cl}$ bonds. Employing the even stronger Si-F bond could potentially lead to an even more efficient CVD chemistry, however, fluorinated chemistry is very poorly understood for SiC CVD. Here, we present studies of the poorly understood fluorinated CVD chemistry for homoepitaxial SiC layers using $\mathrm{SiF}_{4}$ as $\mathrm{Si}$ precursor. We use a combination of experimental growth studies, thermal equilibrium calculations of gas phase composition and quantum chemical computations (i.e. hybrid density functional theory) of the surface chemistry to probe the silicon chemistry in the CVD process. We show that while growth rates on the order of $35 \mu \mathrm{m} / \mathrm{h}$ can be achieved with a fluorinated chemistry, the deposition chemistry is very sensitive to the mass flows of the precursors and not as robust as the chlorinated CVD chemistry which routinely yields $100 \mu \mathrm{m} / \mathrm{h}$ over wide conditions. By using the position for the onset of epitaxial growth along the gas flow direction as a measurable, together with modeling, we conclude that $\mathrm{SiF}$ is the main $\mathrm{Si}$ growth species with $\mathrm{SiHF}$ as a minor $\mathrm{Si}$ species contributing to growth. 


\section{Introduction}

The material properties of silicon carbide (SiC) make it suitable for high power semiconductor devices, ${ }^{1,2}$ where its wide band gap ( $3.26 \mathrm{eV}$ for the $4 \mathrm{H}$-SiC polytype) and high electric breakdown field strength $\left(2 \cdot 10^{6} \mathrm{~V} / \mathrm{cm}\right)$ make it possible to block high voltages. Chemical vapor deposition (CVD) is by far the most suitable technique to produce the high quality, thick, low doped epitaxial layers needed for these devices. CVD of epitaxial SiC films is typically done at high temperatures $\left(1500-1750{ }^{\circ} \mathrm{C}\right)$ with the Si and C precursor molecules heavily diluted in a hydrogen carrier gas. A limiting factor for the increase in growth rate by increasing the amount of precursor, is the onset of homogeneous gas phase nucleation - typically formation of silicon clusters - at too high concentrations of precursors in the gas mixture. This limitation can be circumvented by adding chlorine (Cl) to the process, ${ }^{3}$ since it binds stronger to $\mathrm{Si}\left(\mathrm{Si}-\mathrm{Cl} 417 \mathrm{~kJ} / \mathrm{mol}^{4}\right)$ than $\mathrm{Si}$ to $\mathrm{Si}(\mathrm{Si}-\mathrm{Si}$ $310 \mathrm{~kJ} / \mathrm{mol}^{4}$ ), thereby hindering silicon clustering and allowing for a higher precursor concentration and an increased growth rate of epitaxial SiC layers. This chemical route has been thoroughly investigated and developed. ${ }^{5}$ It has recently been shown that bromine $(\mathrm{Br})$ also has the effect of hindering silicon cluster formation and that the growth rate can be further increased by substituting $\mathrm{Cl}$ with $\mathrm{Br}$. The $\mathrm{Si}-\mathrm{Br}$ bond $\left(\mathrm{Si}-\mathrm{Br} 358 \mathrm{~kJ} / \mathrm{mol}^{4}\right)$ is stronger than the $\mathrm{Si}-\mathrm{Si}$ bond but weaker than the Si-Cl bond. The somewhat weaker $\mathrm{Si}-\mathrm{Br}$ bond is believed to lead to lower activation barriers in the gas phase and surface chemistry, leading to the somewhat higher growth rate observed for brominated CVD chemistry compared to chlorinated CVD chemistry. ${ }^{6}$ Further, it has been shown by Rana et al. ${ }^{7}$ that silicon clusters can be fully eliminated by using $\mathrm{SiF}_{4}$ as the Si precursor. This report (Ref. 7) is the first report on using $\mathrm{SiF}_{4}$ as $\mathrm{Si}$ precursor for CVD of $\mathrm{SiC}$ but does not discuss the possible chemistry in a fluorinated CVD route to SiC. The Si-F bond is the strongest Si-halogen bond (Si-F $576 \mathrm{~kJ} / \mathrm{mol}^{4}$ ) which makes $\mathrm{SiF}_{4}$ a very stable molecule. The 
mechanisms behind growth with such a stable molecule therefore become interesting, why we here further investigate the fluorinated chemistry. We employ a combination of CVD experiments and thermochemical and quantum chemical modelling in an effort to elucidate the chemistry of the silicon species in fluorinated CVD of SiC. In the extension, these results will be important for an overall understanding of halogenated CVD of SiC.

\section{Methods}

\section{Experimental details.}

SiC samples were grown using an inductively heated horizontal hot wall CVD system. The precursors $\mathrm{SiF}_{4}$ and $\mathrm{C}_{2} \mathrm{H}_{4}$ were diluted in $\mathrm{Pd}$ membrane purified $\mathrm{H}_{2}$ and introduced through a quartz liner connected via a graphite continuation to the susceptor. The susceptor, $190 \mathrm{~mm}$ long, $78 \mathrm{~mm}$ wide and $24 \mathrm{~mm}$ high in inner dimensions, was positioned in an RF heated graphite container which on the outside was isolated with rigid graphite. The whole package was then placed in a quartz tube. SiC substrates of $4 \mathrm{H}$ Si-face $4^{\circ}$ off-cut in the $(11-20)$ direction, $16 \times 16 \mathrm{~mm}^{2}$ in size, were placed at certain positions along the center line of the susceptor bottom. For the experiments, the temperatures were $1600{ }^{\circ} \mathrm{C}$ and $1650{ }^{\circ} \mathrm{C}$, the pressure was 100 mbar and the carrier gas flow was 25 standard l/min (SLM) as well as 37.5 SLM where explicitly written. The precursor gas flow ratios $\mathrm{Si} / \mathrm{H}_{2}$ and $\mathrm{C} / \mathrm{Si}$ were varied between $0.125 \%-1.0 \%$ and $0.125-1.2$, respectively. To emphasize that these ratios are determined from the flow of precursors, controlled by electronic mass flow controllers going into the growth chamber, they will be referred to as inlet ratios throughout this paper. 
As $\mathrm{SiF}_{4}$ is used together with hydrogen, the formation of hydrogen fluoride (HF) inside the quartz tube is inevitable. Security precautions related to HF as a byproduct from the process is discussed in the Supporting information. ${ }^{8}$ No etching of the reactor's quartz tube could, however, be seen, which is well in line with previous findings, that quartz is not etched by HF unless water is present ${ }^{9}$ and the temperature of the quartz is below $\sim 700{ }^{\circ} \mathrm{C}^{10}$. Detailed CFD simulations show that the temperature on the quartz tube, and the gas close to it, downstream of the susceptor, is around $200^{\circ} \mathrm{C}$, even though the gas leaving the susceptor has a much higher temperature. This is because of the vortices created in the gas at the susceptor exit, which leads to a good mixing of hot and cool gas closer to the quartz tube wall, and the slow backflow of cool gas closest to the quartz tube wall that is an effect of the vortices createdThe thickness of the epitaxial layers was measured from the sample cross section in a scanning electron microscope (SEM) after the sample had been cleaved. Approximately $2 \mathrm{~mm}$ from each side of the sample were excluded to avoid edge effects.

\section{Thermodynamic equilibrium modelling.}

To understand the SiC growth process better, various modeling methods can be used to estimate the composition of the gas mixture at the growth surface, which species contribute to growth, and the rate of surface reactions that determine e.g. the growth rate. The composition of the gas mixture is a result of a vast number of gas phase reactions. It is in principle possible to compose a model with all these reactions and simulate the concentrations of each species in the gas for a realistic representation of the CVD reactor, using e.g. Computational Fluid Dynamics (CFD). However, the necessary input data for such a model, such as reaction rate constants or activation energies, are not easily obtained or found in literature. On the other hand, temperatures in the SiC CVD process are very high and thus gas phase reactions will be fast. The typical mean time for the gas phase 
reactions is of the order of nanoseconds, while the residence time for the gas in the hot zone of the reactor is of the order of 0.1 seconds at typical growth conditions. This means that, as an approximation, we can use thermodynamic equilibrium calculations to estimate the gas phase composition at various process conditions.

Here, thermodynamic equilibrium in the Si-C-F-H system was calculated by minimization of Gibbs free energy for the conditions $\mathrm{T}=1600{ }^{\circ} \mathrm{C}, \mathrm{p}=100 \mathrm{mbar}$, inlet $\mathrm{Si} / \mathrm{H}_{2}=0.25 \%$, inlet $\mathrm{C} / \mathrm{Si}=1.0$, inlet $\mathrm{F} / \mathrm{Si}=4.0$. Then, one parameter at a time was varied, while keeping the others constant at their standard value. Since one can choose which species that are allowed to form in such calculations, there is a risk that wrong conclusions might be drawn if the set of molecules is too limited. Here, we have allowed in total 153 different species to form, with their thermochemical properties taken from recent and updated literature sources. The set of allowed species include hydrocarbons and silicon hydrides with up to five carbon or silicon atoms, organosilicon species with one and two silicon atoms and up to four carbon atoms, ${ }^{11}$ pure carbon and silicon molecules from $\mathrm{C}$ to $\mathrm{C}_{6}$ and $\mathrm{Si}$ to $\mathrm{Si}_{6}$, and all $\mathrm{Si}_{\mathrm{x}} \mathrm{C}_{\mathrm{y}}$ where $2 \leq \mathrm{x}+\mathrm{y} \leq 6,{ }^{12}$ as well as the complete sets of the $\mathrm{SiH}_{\mathrm{n}} \mathrm{F}_{\mathrm{m}}$ and $\mathrm{CH}_{\mathrm{n}} \mathrm{F}_{\mathrm{m}}$ molecules $(\mathrm{n}+\mathrm{m} \leq 4) .{ }^{13}$ No condensed phases were allowed to from, $\mathrm{a}$ common approach for probing the gas-phase composition before it reaches the substrate, but the larger $\mathrm{Si}$ and $\mathrm{Si}-\mathrm{C}$ molecules (such as $\mathrm{Si}_{6}$ or $\mathrm{Si}_{5} \mathrm{C}$ ) could be thought of as embryos to solid particles in the gas.

The equilibrium calculations give the approximate composition of the gas phase at the selected conditions. However, there is a concentration gradient towards the surface caused by the deposition of species, and the mass transport to the surface is driven by this gradient. Therefore the concentration at the surface will not be the same as further above the surface, even if the temperatures are the same. One commonly used approach to estimate the concentrations of each 
species at a surface is by using the Maxwell-Boltzmann velocity distribution, so that the number of moles striking the surface per unit area and unit time is

$$
\Phi_{i}=\frac{p_{i}}{\sqrt{2 \pi M_{i} R T}}
$$

where $p_{i}$ is the partial pressure of species $i$, and $M_{i}$ its molar mass. This expression provides a reasonably good approximation, and it has been used for the analysis below to derive the variation in impingement rate depending on temperature, inlet $\mathrm{Si} / \mathrm{H}_{2}$ ratio and inlet $\mathrm{C} / \mathrm{Si}$ ratio.

\section{Surface chemistry modelling.}

Thermodynamic equilibrium computations enable prediction of the gas phase composition as the system approaches equilibrium and gives us an idea of which species that are likely to be present in the gas phase. To determine whether or not these species actively participate in the growth, and if so to what degree, requires the knowledge of the process Gibbs free energies. For this, we have used quantum chemical hybrid density functional theory (DFT) to study the gas species reactions with the surface, where we modeled the adsorption process using a $\mathrm{SiC}$ cluster, $\mathrm{Si}_{13} \mathrm{C}_{13} \mathrm{H}_{32}$, which consists of two Si-C bilayers. The perfect symmetry of a SiC slab has been retained by terminating the dangling bonds near the edges with hydrogen atoms. The Si face of the cluster, namely the (0001) surface, was chosen as the adsorption surface which provided a planar area of 3 interconnected hexagonal SiC rings. The correct Si-C stoichiometry has been imposed for all cases. To accommodate the landing of a Si species we assumed the presence of either a methyl (- $\left.\mathrm{CH}_{3}\right)$ or a methylene $\left(\mathrm{CH}_{2}\right)$ group already attached to the surface as the adsorption site.

The quantum chemical calculations were performed using the Gaussian 09 software. ${ }^{14}$ The equilibrium structures as well as transition states were optimized using the B3LYP functional ${ }^{15,16}$ 
and the LanL2DZ basis set ${ }^{17,18}$ with dispersion correction (D3) ${ }^{19}$. The systems were allowed to fully relax during the optimization. Harmonic vibrational frequencies were calculated using the same functional, basis set and dispersion correction. To improve the accuracy of energy prediction, we replaced the B3LYP electronic energies with single-point calculated energies using the M06$2 \mathrm{X}$ functional ${ }^{20}$ together with the G3LargeXP basis set from the Gaussian-4 theory. ${ }^{21}$ All transition states were verified by visualizing the displacement from the imaginary frequency vibration or following the intrinsic reaction coordinates to the reactant and product states. The changes in free energies were defined with respect to the reactants in the ground state. From the free energy difference between the transition state (saddle point) and the reactant state, the classical transition state theory provides prediction of the forward reaction rate constant and, as a consequence, the molecular sticking coefficients which is the probability of a molecule to deposit per hit (see Supporting information for detailed derivation ${ }^{8}$ ). The $\mathrm{Si}_{13} \mathrm{C}_{13} \mathrm{H}_{32}$ cluster has been tested against a larger cluster $\left(\mathrm{Si}_{22} \mathrm{C}_{22} \mathrm{H}_{44}\right)$ where it has been shown to provide results in good agreements to the larger cluster for the adsorptions on a methyl group at the same level of calculations as used here in this study. Differences of less than $3 \mathrm{~kJ} / \mathrm{mol}$ for the Gibbs free energies of reactions and less than $10 \mathrm{~kJ} / \mathrm{mol}$ for the Gibbs free energies of activation were observed in between the two different cluster sizes over the temperature range of $400-2200{ }^{\circ} \mathrm{C} .{ }^{8}$

\section{Results}

We note experimentally that the growth rate along the gas flow direction in the susceptor always assumes a profile, schematically shown in Fig. 1. 


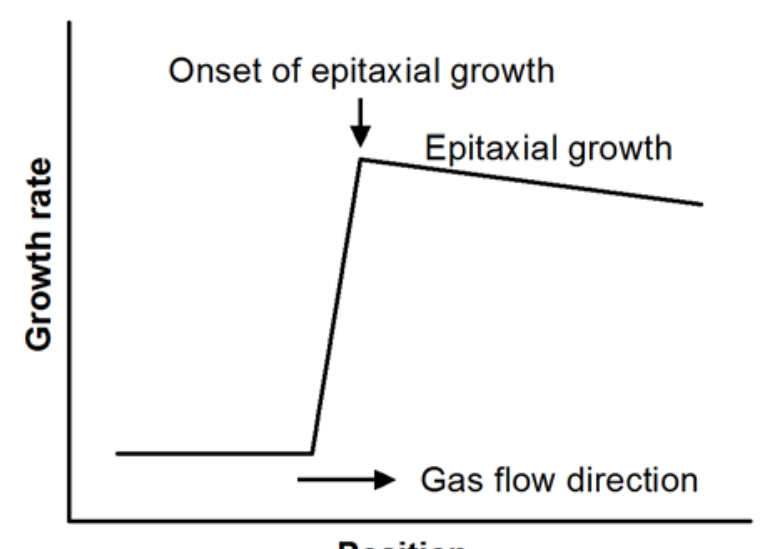

Position

Figure 1. Schematic growth rate versus position in the susceptor, i.e. distance from the inlet.

From the susceptor inlet and a short distance into the susceptor the growth rate is zero or only a few $\mu \mathrm{m} / \mathrm{h}$ until a certain position where an abrupt increase to the maximum growth rate is observed. The spatial extension of the increase, which depends on the process parameters, is typically 1-3 $\mathrm{cm}$ along the susceptor. From the position after this short extension the growth rate slowly decreases along the susceptor. This decrease is similar to what has been observed for chlorinated SiC CVD. ${ }^{22,23}$ After the growth rate increase, at the same position as the growth rate reaches its maximum, the growth also becomes epitaxial. This transition to epitaxial growth is such abrupt that the position for it is easily recognized. This position will in the following be referred to as the onset of epitaxial growth. Prior to the onset of epitaxial growth, the surface is completely covered with triangular surface defects of different sizes and shapes. The onset of the epitaxial growth at the sides of the susceptor is situated closer to the inlet. Here we will discuss the onset position as where it is most downstream observed, i.e. in the middle of the susceptor. The following sections will describe how the position for the onset of epitaxial growth shifts depending of process parameters, i.e. precursor concentrations and temperature.

Related to this, we also note that by changing the temperature and precursor gas flow rates we can also change the height (i.e. maximum growth rate) and slopes of this profile. Changes in carrier 
gas flow did not seem to impact on the position for the onset of epitaxial growth. The growth rates achieved are typically $\sim 20 \mu \mathrm{m} / \mathrm{h}$ when similar experimental setup and parameters in the brominated and the chlorinated chemistries of SiC CVD yields $\sim 100 \mu \mathrm{m} / \mathrm{h} .{ }^{6,24}$

\section{The dependence on the inlet $\mathrm{C} / \mathrm{Si}$ ratio.}

It has been shown for fluorinated CVD of $\mathrm{SiC}$ on on-axis $4 \mathrm{H} \mathrm{SiC} \mathrm{(0001)} \mathrm{substrates} \mathrm{that} \mathrm{the} \mathrm{growth}$ rate is limited by the amount of carbon containing species (C-limited) for higher inlet C/Si ratios. ${ }^{25}$ We find, however, that the onset of epitaxial growth also changes with the inlet C/Si ratio as shown in Fig. 2, where the onset of epitaxial growth shifts downstream in the susceptor for increased inlet C/Si ratio.

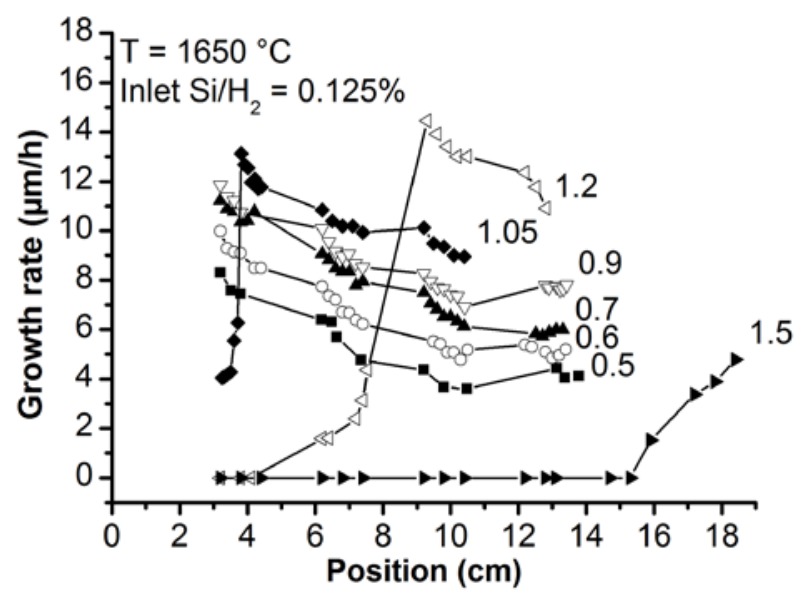

Figure 2. Growth rate profiles for different inlet $\mathrm{C} / \mathrm{Si}$ ratios (labels) at $\mathrm{T}=1650{ }^{\circ} \mathrm{C}$ and inlet $\mathrm{Si} / \mathrm{H}_{2}=0.125 \%$ with $\mathrm{Q}=25 \mathrm{SLM}$. The onset of epitaxial growth shifts with inlet $\mathrm{C} / \mathrm{Si}$ ratio. For inlet $\mathrm{C} / \mathrm{Si}=1.2$ the onset of epitaxial growth is at $\sim 9 \mathrm{~cm}$ from the inlet, for inlet $\mathrm{C} / \mathrm{Si}=1.05$ it is at $\sim 4 \mathrm{~cm}$ and for inlet $\mathrm{C} / \mathrm{Si} \leq 0.9$ it is at $<3 \mathrm{~cm}$. The decline in growth rate after the onset is $\sim 0.5 \mu \mathrm{m} / \mathrm{h} / \mathrm{cm}$.

When increasing the inlet $\mathrm{C} / \mathrm{Si}$ ratio to $\geq 1.5$, the onset of epitaxial growth does not appear within the susceptor length. Also, when lowering the inlet C/Si ratio to 0.9 the onset of epitaxial growth 
appears upstream of the used sample positions. The C/Si ratio is not found to affect the rate of decrease in growth rate which is $\sim 0.5 \mu \mathrm{m} / \mathrm{h} / \mathrm{cm}$ at $1650{ }^{\circ} \mathrm{C}$ and inlet $\mathrm{Si} / \mathrm{H}_{2}=0.125 \%$.

\section{The dependence on the inlet $\mathrm{Si} / \mathrm{H}_{2}$ ratio.}

The $\mathrm{Si} / \mathrm{H}_{2}$ ratio reflects the amount of precursors in the inlet gas mixture which, for SiC CVD, typically affects the growth rate. Here, we also find that the onset of epitaxial growth is shifted downstream when the inlet $\mathrm{Si} / \mathrm{H}_{2}$ is increased, keeping the inlet $\mathrm{C} / \mathrm{Si}$ ratio constant, as seen in Fig. 3. The decline in growth rate in the epitaxial growth region increases with increased $\mathrm{Si} / \mathrm{H}_{2}$ ratio, but is here typically in the range of $1-2 \mu \mathrm{m} / \mathrm{h} / \mathrm{cm}$.

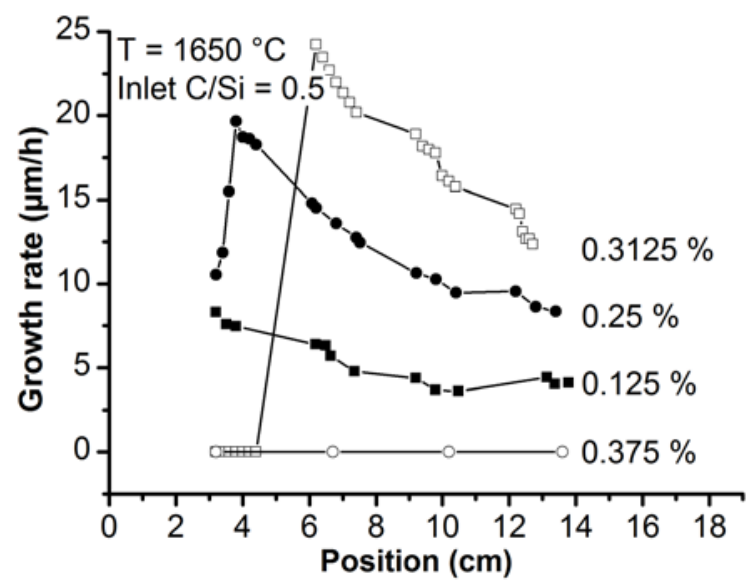

Figure 3. Growth rate profiles for different inlet $\mathrm{Si} / \mathrm{H}_{2}$ ratios (labels) at $\mathrm{T}=1650{ }^{\circ} \mathrm{C}$ and inlet $\mathrm{C} / \mathrm{Si}=0.5 \mathrm{with} \mathrm{Q}=$ 25 SLM. The position for the onset of epitaxial growth shifts with inlet $\mathrm{Si} / \mathrm{H}_{2}$ ratio. For inlet $\mathrm{Si} / \mathrm{H}_{2}=0.125 \%$ the position is $<3 \mathrm{~cm}$ from the inlet, for inlet $\mathrm{Si} / \mathrm{H}_{2}=0.25 \%$ and $0.3125 \%$ it is $\sim 4 \mathrm{~cm}$ and $\sim 6 \mathrm{~cm}$ respectively. For inlet $\mathrm{Si} / \mathrm{H}_{2}=0.375 \%$ position for the onset of epitaxial growth is not observed within $13 \mathrm{~cm}$.

\section{The combined dependence of the inlet $\mathrm{Si} / \mathrm{H}_{2}$ and $\mathrm{C} / \mathrm{Si}$ ratio.}


The onset of epitaxial growth is shifted downstream for both an increase in the inlet $\mathrm{Si} / \mathrm{H}_{2}$ ratio at a given inlet $\mathrm{C} / \mathrm{Si}$ ratio and an increase in the inlet $\mathrm{C} / \mathrm{Si}$ ratios at a given inlet $\mathrm{Si} / \mathrm{H}_{2}$ ratio. The onset of epitaxial growth can in other words be kept at the same position by decreasing one parameter and increasing another. The positions for the onset of epitaxial growth are tabulated in Table 1 and plotted in Fig. 4 for varied inlet $\mathrm{Si} / \mathrm{H}_{2}$ and inlet $\mathrm{C} / \mathrm{Si}$ ratios at $\mathrm{T}=1600{ }^{\circ} \mathrm{C}$.

\begin{tabular}{|l|l|l|}
\hline $\begin{array}{l}\text { Inlet } \mathrm{Si} / \mathrm{H}_{2} \\
\text { ratio (\%) }\end{array}$ & $\begin{array}{l}\text { Inlet C/Si } \\
\text { ratio (1) }\end{array}$ & $\begin{array}{l}\text { Position for Onset } \\
\text { of epitaxial growth } \\
(\mathrm{cm})\end{array}$ \\
\hline 0.125 & 0.8 & 6 \\
\hline 0.125 & 0.9 & 8 \\
\hline 0.125 & 1.0 & $>12$ \\
\hline 0.25 & 0.45 & 6 \\
\hline 0.25 & 0.50 & 11 \\
\hline 0.375 & 0.30 & 5 \\
\hline 0.375 & 0.33 & 8 \\
\hline 0.50 & 0.25 & 6 \\
\hline 1.0 & 0.125 & $<2$ \\
\hline 1.0 & 0.135 & 4 \\
\hline
\end{tabular}

Table 1. Listed positions for the onset of epitaxial growth at temperature $1600^{\circ} \mathrm{C}$ for different combinations of inlet $\mathrm{Si} / \mathrm{H}_{2}$ and inlet $\mathrm{C} / \mathrm{Si}$ ratios.

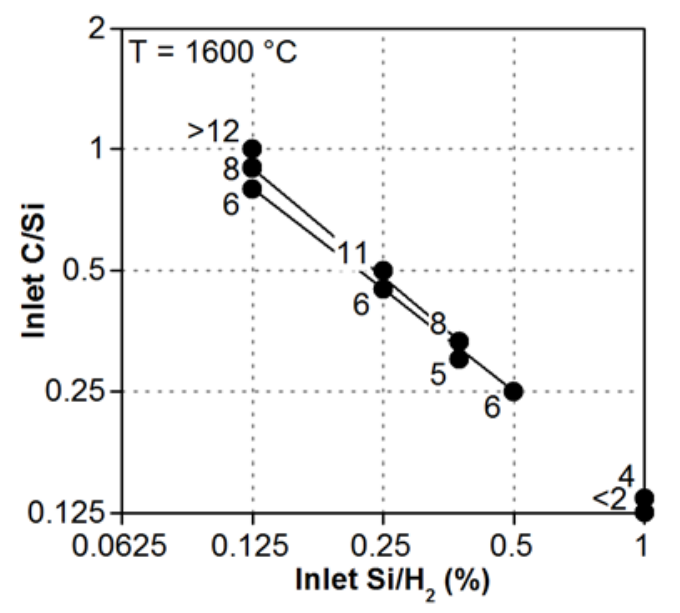

Figure 4. The position for the onset of epitaxial growth as labels in the unit of $\mathrm{cm}$ from the susceptor inlet depending on inlet $\mathrm{Si} / \mathrm{H}_{2}$ and inlet $\mathrm{C} / \mathrm{Si}$ ratios at $160{ }^{\circ} \mathrm{C}$ and $\mathrm{Q}=25 \mathrm{SLM}$. Lines are inserted to connect the points with the same position for the onset of epitaxial growth $(6 \mathrm{~cm}$ and $8 \mathrm{~cm})$. Note the $\log _{2}$ scale of the axes. The onset of epitaxial growth can be kept constant by changing the two ratios simultaneously. 
Here it can be noticed that there are growth parameters that give the same position for the onset of epitaxial growth; two positioned at $\sim 8 \mathrm{~cm}$ for [inlet $\mathrm{Si} / \mathrm{H}_{2}$, inlet $\left.\mathrm{C} / \mathrm{Si}\right]=[0.125 \%$, 0.9] and [inlet $\mathrm{Si} / \mathrm{H}_{2}$, inlet $\left.\mathrm{C} / \mathrm{Si}\right]=[0.375 \%, 0.33]$, as well as three points having the same position for the onset of epitaxial growth at $\sim 6 \mathrm{~cm}$ for the [inlet $\mathrm{Si} / \mathrm{H}_{2}$, inlet $\mathrm{C} / \mathrm{Si}$ ] ratio values $[0.125 \%, 0.8]$, [0.25 \%, 0.45] and [0.50 \%, 0.25]. These two lines, seen in Fig. 4, connecting the same positions exemplify that these positions are changed upstream for both a lower inlet $\mathrm{Si} / \mathrm{H}_{2}$ ratio and lower inlet $\mathrm{C} / \mathrm{Si}$ ratio, i.e. towards the lower left corner in the figure. At the same time it is possible to see that small changes in the inlet ratios causes significant shifts in these positions. To keep the onset of epitaxial growth constant, the two parameters have to be changed almost oppositely.

This relationship between the parameters can also be visualized by relating the $\mathrm{C}$ precursor flow to inlet $\mathrm{H}_{2}$ flow as inlet $\mathrm{C} / \mathrm{H}_{2}$ instead of to the inlet $\mathrm{Si} / \mathrm{H}_{2}$ flow as inlet $\mathrm{C} / \mathrm{Si}$. The inlet $\mathrm{C} / \mathrm{H}_{2}$ flow is related to the inlet $\mathrm{Si} / \mathrm{H}_{2}$ and inlet $\mathrm{C} / \mathrm{Si}$ as

$$
\text { inlet } \frac{\mathrm{C}}{\mathrm{H}_{2}}=\text { inlet } \frac{\mathrm{Si}}{\mathrm{H}_{2}} \times \text { inlet } \frac{\mathrm{C}}{\mathrm{Si}} \text {, }
$$

which remains constant if one parameter is doubled and the other halved. This is shown in Fig. 5, where the positions for the onset of epitaxial growth are plotted as inlet $\mathrm{Si} / \mathrm{H}_{2}$ versus inlet $\mathrm{C} / \mathrm{H}_{2}$.

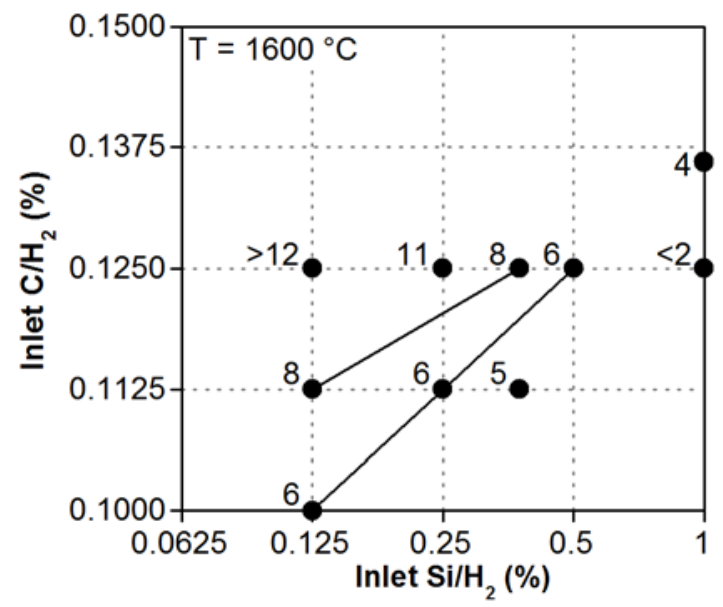


Figure 5. The position for the onset of epitaxial growth. The labels indicate distance in cm from the susceptor inlet depending on inlet $\mathrm{Si} / \mathrm{H}_{2}$ and inlet $\mathrm{C} / \mathrm{H}_{2}$ ratios at $1600{ }^{\circ} \mathrm{C}$ for $\mathrm{Q}=25 \mathrm{SLM}$. Lines are inserted to connect the points with the same position for the onset of epitaxial growth $(6 \mathrm{~cm}$ and $8 \mathrm{~cm})$. The inlet $\mathrm{C} / \mathrm{H}_{2}$ axis is linear and the inlet $\mathrm{Si} / \mathrm{H}_{2}$ axis is in $\log _{2}$ scale. Note the narrow scale of the inlet $\mathrm{C} / \mathrm{H}_{2}$ compared to inlet $\mathrm{Si} / \mathrm{H}_{2}$. The positions for the onset shift upstream for increased inlet $\mathrm{Si} / \mathrm{H}_{2}$ at constant inlet $\mathrm{C} / \mathrm{H}_{2}$ and downstream for increased inlet $\mathrm{C} / \mathrm{H}_{2}$ at constant inlet Si/H2.

The figure shows for the position of onset of epitaxial growth at $6 \mathrm{~cm}$ that the amount of $C$ precursor should be increased by only $25 \%$ while the amount of Si precursor should be increased by $400 \%$ to maintain the position, and thereby how much more sensitive the position for the onset of epitaxial growth is to changes in the amount of C precursor compared to the amount of Si precursor, and also that the inlet $\mathrm{C} / \mathrm{H}_{2}$ has to be reduced if the inlet $\mathrm{Si} / \mathrm{H}_{2}$ is reduced to maintain a constant onset of epitaxial growth position.

\section{The dependence on temperature.}

The influence of temperature on the position for the onset of epitaxial growth at temperatures $T=$ $1600{ }^{\circ} \mathrm{C}$ and $\mathrm{T}=1650^{\circ} \mathrm{C}$ is shown in Fig. 6 , where it is seen that the onset shifts upstream for higher temperatures. 


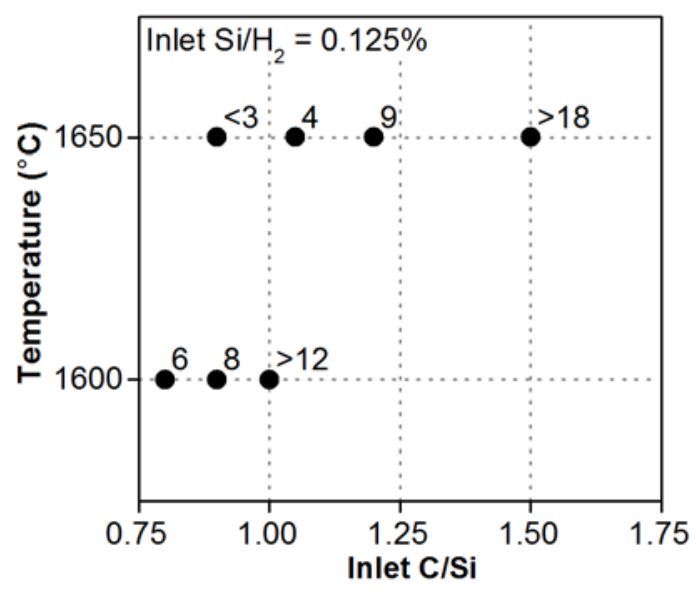

Figure 6. Onset of epitaxial growth positions when temperature and inlet $\mathrm{C} / \mathrm{Si}$ are varied for inlet $\mathrm{Si} / \mathrm{H}_{2}=0.125 \%$ and $\mathrm{Q}=25 \mathrm{SLM}$. The positions for the onset of epitaxial growth are shifted upstream with increased temperature for comparable parameters.

\section{The growth rate.}

Since the growth rate decreases along the gas flow direction, and the position where the growth rate has its maximum also varies for varying process parameters, it is difficult to find suitable values/positions for comparing growth rates at different conditions. By increasing the carrier gas flow rate by $50 \%$ (from 25 SLM to 37.5 SLM), the slope of the decreasing growth rate along the gas flow direction was reduced, while maintaining the maximum growth rate for the same precursor flow rates. Fig. 7 shows the maximum growth rates vs. inlet $\mathrm{Si} / \mathrm{H}_{2}$ ratio at $\mathrm{T}=1600{ }^{\circ} \mathrm{C}$. Here, the inlet $\mathrm{C} / \mathrm{H}_{2}=0.125 \%$ was used. The variation in the growth rate shown here is not linear, although increasing for higher inlet $\mathrm{Si} / \mathrm{H}_{2}$ ratios. Based on the growth rate and amount of precursors used, we estimate the precursor utilization to be approximately $10 \%$. 


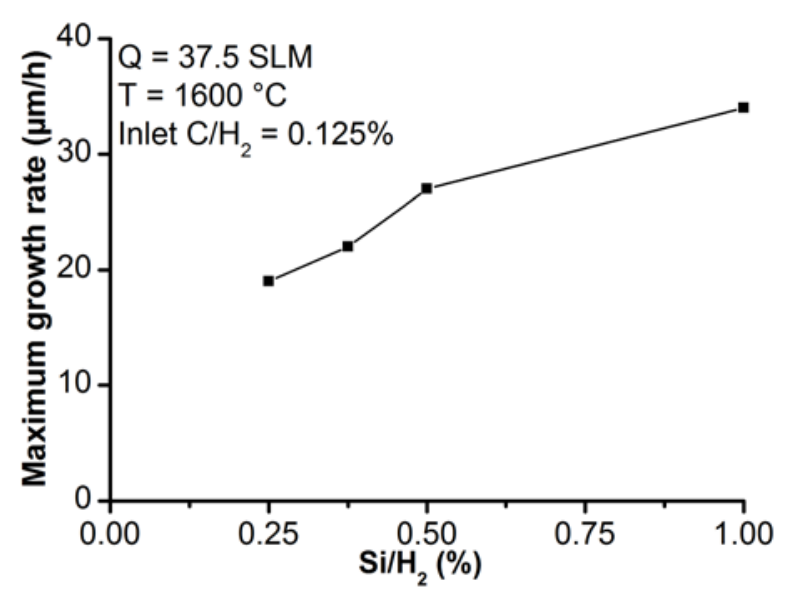

Figure 7. Measured maximum growth rates for different inlet $\mathrm{Si} / \mathrm{H}_{2}$ ratios at $\mathrm{T}=1600{ }^{\circ} \mathrm{C}$ and $\mathrm{Q}=37.5 \mathrm{SLM}$.

\section{Thermodynamic equilibrium calculations.}

Under the assumptions made in the methods section we used thermodynamic equilibrium calculations to predict the gas phase composition and the impingement rates of each species (derived using Eq. 1), when varying temperature at constant inlet $\mathrm{Si} / \mathrm{H}_{2}$ and $\mathrm{C} / \mathrm{Si}$ ratios of $0.25 \%$ and 0.5 , respectively, and when varying inlet $\mathrm{Si} / \mathrm{H}_{2}$ ratio at constant temperature and inlet $\mathrm{C} / \mathrm{Si}$ ratio of $1600{ }^{\circ} \mathrm{C}$ and 0.5 , respectively, as well as when varying inlet $\mathrm{Si} / \mathrm{H}_{2}$ ratio at constant inlet $\mathrm{C} / \mathrm{H}_{2}$ ratio and temperature of $0.125 \%$ and $1600{ }^{\circ} \mathrm{C}$, respectively. The species with the highest impingement rates are shown in Fig. 8.

Experimentally, growth rates were shown to be in the range of $\sim 5-35 \mu \mathrm{m} / \mathrm{h} .10 \mu \mathrm{m} / \mathrm{h}$ corresponds to an adsorption rate of $\sim 2 \cdot 10^{-4} \mathrm{~mol} / \mathrm{m}^{2} / \mathrm{s}$ for each element. ${ }^{8}$ Therefore, all gas species with an impingement rate lower than $2 \cdot 10^{-5} \mathrm{~mol} / \mathrm{m}^{2} / \mathrm{s}$, corresponding to a maximum growth rate of $\sim 1 \mu \mathrm{m} / \mathrm{h}$, are excluded in the further discussion, since their contribution to the growth is considered to be less important. Gas species with an impingement rate higher than $2 \cdot 10^{-5} \mathrm{~mol} / \mathrm{m}^{2} / \mathrm{s}$ at these conditions are, ordered by impingement rate, $\mathrm{SiF}_{2}, \mathrm{C}_{2} \mathrm{H}_{2}, \mathrm{CH}_{4}, \mathrm{SiF}, \mathrm{SiHF}, \mathrm{CH}_{3}, \mathrm{Si}_{1} \mathrm{SiF}_{4}, \mathrm{SiHF}_{3}$, 
$\mathrm{C}_{2} \mathrm{H}_{4}, \mathrm{SiH}_{2}, \mathrm{Si}_{2} \mathrm{C}, \mathrm{SiCH}_{2}, \mathrm{SiH}_{2} \mathrm{SiF}_{3}$ and $\mathrm{SiC}_{2}$. To clarify, species with two $\mathrm{C}$ or $\mathrm{Si}$ atoms, e.g. $\mathrm{C}_{2} \mathrm{H}_{2}$ and $\mathrm{Si}_{2} \mathrm{C}$, need half the impingement rate compared to a species with one $\mathrm{C}$ and/or $\mathrm{Si}$ species, i.e. $1 \cdot 10^{-5} \mathrm{~mol} / \mathrm{m}^{2} / \mathrm{s}$, to provide a C or Si impingement rate on the surface of $2 \cdot 10^{-5} \mathrm{~mol} / \mathrm{m}^{2} / \mathrm{s}$. 

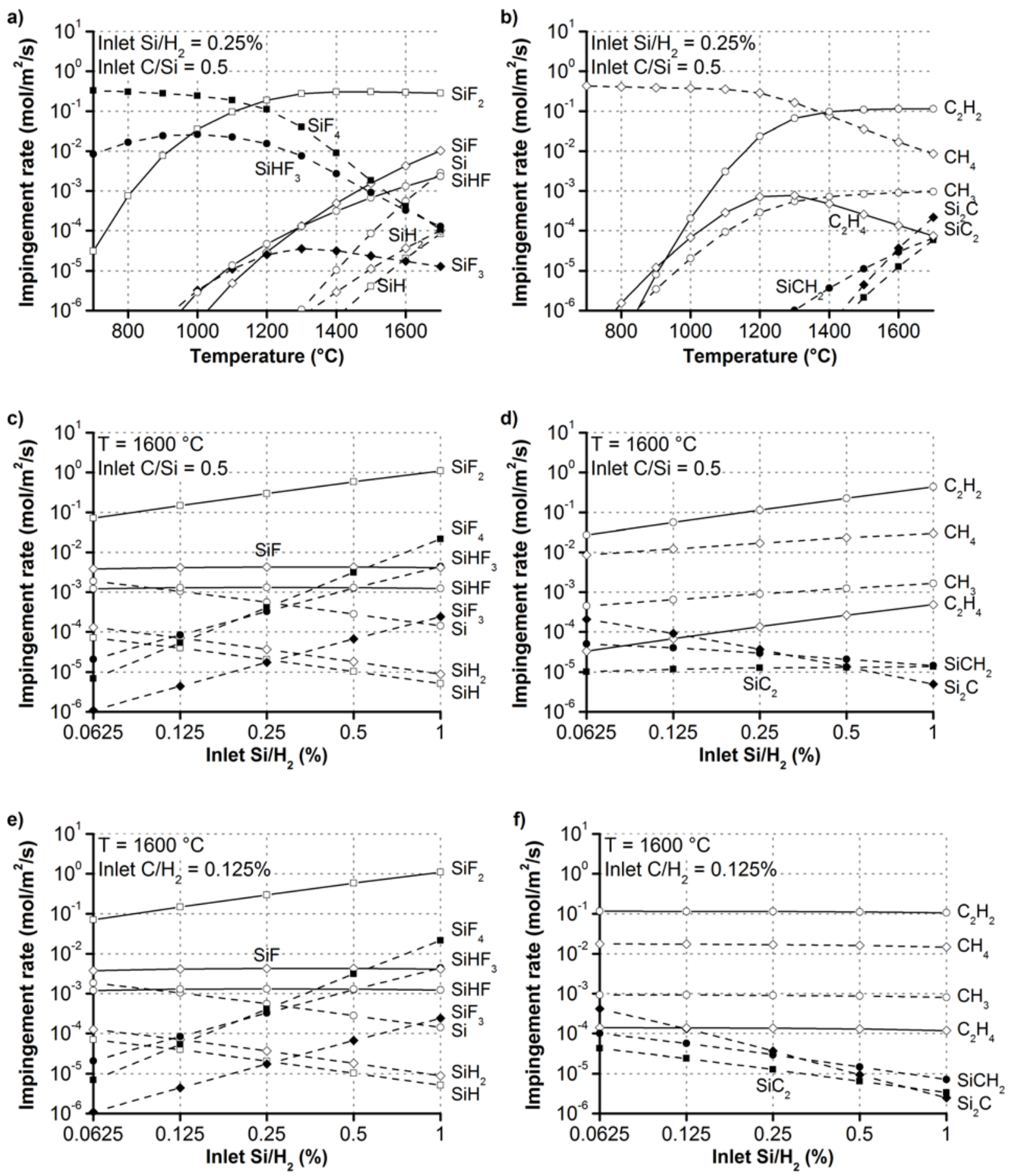

Figure 8. Impingement rates derived from thermodynamic equilibrium concentrations. a) and b) show the dependence on temperature. c) and d) show the dependence on inlet $\mathrm{Si} / \mathrm{H}_{2}$ when the inlet $\mathrm{C} / \mathrm{Si}=0.5$, i.e. varying also $\mathrm{C} / \mathrm{H}_{2}$. e) and f) show the dependence on inlet $\mathrm{Si} / \mathrm{H}_{2}$ when inlet $\mathrm{C} / \mathrm{H}_{2}=0.125 \%$. a), c) and e) show the species 
without $\mathrm{C}$, while b), d) and f) the species containing $\mathrm{C} . \mathrm{F} / \mathrm{Si}=4$ in all calculations. The impingement rate scales in the plots are $\log _{10}$ and the inlet $\mathrm{Si} / \mathrm{H}_{2}$ scales are $\log _{2}$.

\section{Summary of the results.}

The position for the onset of epitaxial growth is significantly dependent on the inlet $\mathrm{C} / \mathrm{H}_{2}$ ratio at $\mathrm{T}=1600{ }^{\circ} \mathrm{C}$, but not significantly dependent on the inlet $\mathrm{Si} / \mathrm{H}_{2}$ ratio. The position for the onset of epitaxial growth is also dependent on temperature. Higher inlet $\mathrm{C} / \mathrm{H}_{2}$ ratios and lower temperature shifts the position for the onset of epitaxial growth downstream. There is a weak dependence of the growth rate on the inlet $\mathrm{Si} / \mathrm{H}_{2}$ ratio. Thermodynamic equilibrium calculations show that several species have enough impingement rate to ascribe for the observed growth rate.

\section{Discussion}

To determine what species are involved in the growth, i.e. growth species, the experimentally observed positions for the onset of epitaxial growth and growth rates are compared to calculated $\mathrm{C} / \mathrm{Si}$ impingement ratios of plausible combinations of species and impingement rates of species. From combinations where a good agreement is found we achieve growth species candidates. As the thermodynamic equilibrium calculations made here only consider the gas phase, we investigate the surface reactivity of these candidates using density functional theory. This "sorting-out" strategy will tell what Si species are involved in the growth in the fluorinated chemistry.

We have observed experimentally that epitaxial growth starts at a certain position in the susceptor - referred to as the onset of epitaxial growth. This is a phenomenon, to our knowledge, not previously discussed in SiC CVD. To discuss the origin of this we first summarize what influences 
the position for the onset of epitaxial growth. We have observed that the position for the onset of epitaxial growth is influenced by the inlet $\mathrm{C} / \mathrm{Si}$ ratio, and by the inlet $\mathrm{Si} / \mathrm{H}_{2}$ ratio (Fig. 4). Fig 9 sketches the growth rate at a constant position in the susceptor for changed inlet $\mathrm{C} / \mathrm{Si}$ (or $\mathrm{C} / \mathrm{H}_{2}$ ) ratio at a constant inlet $\mathrm{Si} / \mathrm{H}_{2}$ ratio observed by us (marked by "Experimental range" in the figure) together with what is normally seen for SiC CVD at low C/Si ratios i.e. C and Si limited regimes.

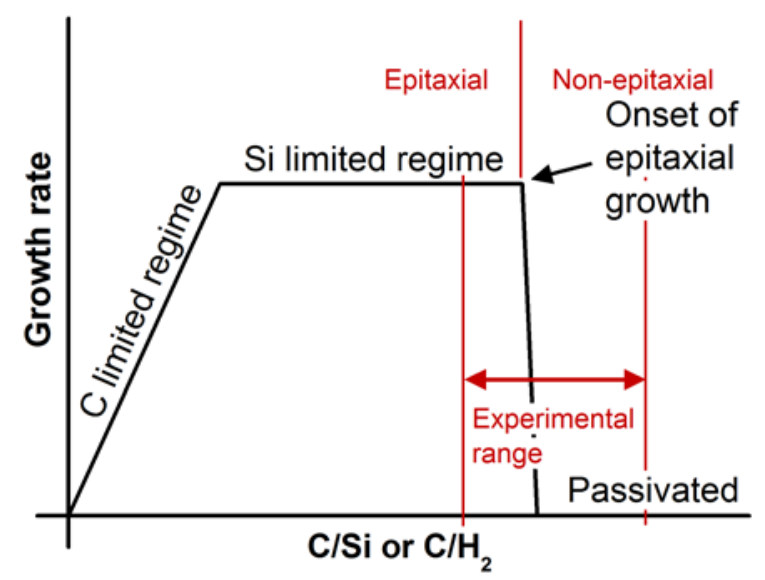

Figure 9. Sketch of growth rate for different amounts of $C$ precursor marked with different growth regimes.

We speculate in that the non-epitaxial growth (approaches $0 \mu \mathrm{m} / \mathrm{h}$ ) is related to a surface passivation related to the impingement of $\mathrm{C}$ growth species - probably by a H-termination of the surface originating from that the $\mathrm{H}$ is still bound to its $\mathrm{C}$ from the $\mathrm{C}_{\mathrm{x}} \mathrm{H}_{\mathrm{y}}$ growth species, now adsorbed on the surface.

Since the changes to the inlet precursor concentrations also influence the gas phase composition, and thereby the impingement rate of the different $\mathrm{C}$ and $\mathrm{Si}$ species, a connection between the onset of epitaxial growth and the $\mathrm{C} / \mathrm{Si}$ impingement ratio is expected. The position of the onset of epitaxial growth is also influenced by the inlet $\mathrm{Si} / \mathrm{H}_{2}$ ratio for constant inlet $\mathrm{C} / \mathrm{Si}$ ratio, and therefore it is likely that the $\mathrm{C} / \mathrm{Si}$ impingement ratio of the species contributing to the growth, referred to as the $\mathrm{C} / \mathrm{Si}$ impingement ratio, can change, even if the inlet $\mathrm{C} / \mathrm{Si}$ ratio is constant. Since the inlet $\mathrm{Si} / \mathrm{H}_{2}$ 
and inlet $\mathrm{C} / \mathrm{Si}$ ratio can be altered to hold a constant onset of epitaxial growth position, we can assume that the $\mathrm{C} / \mathrm{Si}$ impingement ratio is approximately the same for a certain position for the onset of epitaxial growth at the same time as the impingement rates of these species correlate to growth rate trends. By comparing trends in experimental growth rates and positions for the onset of epitaxial growth to trends in calculated impingement rates of different species when varying the CVD process conditions, it is possible to tie specific species to the experimental observations. The trajectory in parameter space at which the position for the onset of epitaxial growth can be kept constant will be used to identify growth species candidates.

Experiments show that the growth rate increases with increased inlet $\mathrm{Si} / \mathrm{H}_{2}$ ratio for a constant $\mathrm{C} / \mathrm{H}_{2}$ ratio (Fig. 7). The impingement rates of the growth species are therefore not expected to decrease with increased $\mathrm{Si} / \mathrm{H}_{2}$ ratio. From the equilibrium calculations we see that the atomic $\mathrm{Si}$, $\mathrm{SiH}, \mathrm{SiH}_{2}, \mathrm{SiCH}_{2}, \mathrm{Si}_{2} \mathrm{C}$ and $\mathrm{SiC}_{2}$ species all decrease with increased inlet $\mathrm{Si} / \mathrm{H}_{2}$ ratio (Fig. 8e-f) and they are therefore not expected to be growth species in the fluorinated chemistry for SiC CVD. Further, $\mathrm{SiF}_{3}, \mathrm{SiHF}_{3}$ and $\mathrm{SiF}_{4}$ increase fast with increased inlet $\mathrm{Si} / \mathrm{H}_{2}$ ratio to a rate which does not scale to the observed growth rate change (Fig. 7). Furthermore $\mathrm{SiHF}_{3}$ and $\mathrm{SiF}_{4}$ are closed-shell molecules and are hence less reactive while $\mathrm{SiF}_{3}$ impingement rate decreases with increased temperature and is well below $2 \cdot 10^{-4} \mathrm{~mol} / \mathrm{m}^{2} / \mathrm{s}$ for inlet $\mathrm{Si} / \mathrm{H}_{2}=0.125 \%$, indicating that these species are not growth species either. Candidates for being Si growth species based on their impingement, impingement rate trends for varying inlet $\mathrm{Si} / \mathrm{H}_{2}$ ratio and reactivity can thus only be $\mathrm{SiF}_{2}$, SiF and SiHF.

The different $\mathrm{C}$ containing species can be evaluated in a similar manner as the Si species. The impingement rates for the species $\mathrm{SiC}_{2}, \mathrm{Si}_{2} \mathrm{C}$ and $\mathrm{SiCH}_{2}$ decrease with increased inlet $\mathrm{Si} / \mathrm{H}_{2}$ ratio to well below an impingement rate of $2 \cdot 10^{-4} \mathrm{~mol} / \mathrm{m}^{2} / \mathrm{s}$ and are therefore excluded as candidates for 
being $\mathrm{C}$ growth species. Remaining $\mathrm{C}$ growth species candidates are thus $\mathrm{C}_{2} \mathrm{H}_{2}, \mathrm{CH}_{4}, \mathrm{CH}_{3}$ and $\mathrm{C}_{2} \mathrm{H}_{4}$, which all show similar trends when varying inlet $\mathrm{C} / \mathrm{Si}$ (and/or inlet $\mathrm{Si} / \mathrm{H}_{2}$ ) at growth temperature $1600^{\circ} \mathrm{C}$, although with different impingement rates. Therefore any of the C growth species candidates can be used in this study to determine the C/Si impingement ratio trends for the Si growth species candidates, even though some discussion can be of interest. $\mathrm{CH}_{4}$ is a stable closed-shell molecule and therefore not particularly surface reactive compared to $\mathrm{CH}_{3}$, which on the other hand has a lower impingement rate than $\mathrm{CH}_{4} \cdot \mathrm{C}_{2} \mathrm{H}_{4}$ has an impingement rate about $\sim 1000$ times lower than $\mathrm{C}_{2} \mathrm{H}_{2}$, fairly close to an impingement rate of $1 \cdot 10^{-4} \mathrm{~mol} / \mathrm{m}^{2} / \mathrm{s}$. $\mathrm{C}_{2} \mathrm{H}_{2}$ and $\mathrm{CH}_{3}$ both follow the same trends in temperature and concentrations, although the impingement rate of $\mathrm{C}_{2} \mathrm{H}_{2}$ is 125 times higher than the impingement rate of $\mathrm{CH}_{3}$. For the sake of simplicity, we will use $\mathrm{C}_{2} \mathrm{H}_{2}$ in the further discussion in the comparison to the Si species. If $\mathrm{CH}_{4}$ would have been used, the $\mathrm{C} / \mathrm{Si}$ impingement ratio would have been scaled by $\sim 0.15$; for $\mathrm{CH}_{3}$ by $\sim 0.008$ and for $\mathrm{C}_{2} \mathrm{H}_{4}$ by $\sim 0.001$.

Three species combinations will now be discussed further; $\mathrm{C}_{2} \mathrm{H}_{2}+\mathrm{SiF}_{2}, \mathrm{C}_{2} \mathrm{H}_{2}+\mathrm{SiF}$ and $\mathrm{C}_{2} \mathrm{H}_{2}+\mathrm{SiHF}$. The impingement of $\mathrm{SiF}_{2}$ varies with the inlet $\mathrm{Si} / \mathrm{H}_{2}$, for inlet $\mathrm{C} / \mathrm{H}_{2}=0.125 \%$ as shown in Fig. 8e i.e. it does not follow the trends of the four $\mathrm{C}$ species discussed above, which have approximately constant impingement rate, independent of inlet $\mathrm{Si} / \mathrm{H}_{2}$ shown in Fig. 8f. This gives a $\mathrm{C} / \mathrm{Si}$ impingement ratio trend that is significantly dependent on the inlet $\mathrm{Si} / \mathrm{H}_{2}$ ratio at constant inlet $\mathrm{C} / \mathrm{H}_{2}$ ratio, which is in contradiction to what is shown in Fig. 5, where experiments show that the onset of epitaxial growth is not strongly dependent on the inlet $\mathrm{Si} / \mathrm{H}_{2}$ ratio at constant inlet $\mathrm{C} / \mathrm{H}_{2}$ ratio. Due to the poor agreement between the onset of epitaxial growth and the $\mathrm{C} / \mathrm{Si}$ impingement ratio, we therefore do not believe that $\mathrm{SiF}_{2}$ is a $\mathrm{Si}$ growth species. This is similar to chlorinated and brominated chemistries in which neither $\mathrm{SiCl}_{2}$ nor $\mathrm{SiBr}_{2}$ are considered to be a 
significant Si growth species. ${ }^{6}$ That $\mathrm{SiF}_{2}$ does not seem to take part in growth - even though it has a high impingement rate - is further discussed below when the surface reactions are analyzed by quantum-chemical computations.

For the other two combinations $\mathrm{C}_{2} \mathrm{H}_{2}+\mathrm{SiF}$ and $\mathrm{C}_{2} \mathrm{H}_{2}+\mathrm{SiHF}$ it can be noted from Fig. 8e that the impingement rate from $\mathrm{SiF}$ and $\mathrm{SiHF}$ are nearly constant with respect to inlet $\mathrm{Si} / \mathrm{H}_{2}$ (in contrast to the impingement rate of $\mathrm{SiF}_{2}$ ), which is also the case for the four hydrocarbons, shown in Fig 8f. The behaviors of the species combinations $\mathrm{C}_{2} \mathrm{H}_{2}+\mathrm{SiF}$ and $\mathrm{C}_{2} \mathrm{H}_{2}+\mathrm{SiHF}$ are almost identical to each other and clearly different from the $\mathrm{C}_{2} \mathrm{H}_{2}+\mathrm{SiF}_{2}$ combination. The most prominent difference between the two is that the $\mathrm{C} / \mathrm{Si}$ impingement ratio is $\sim 3$ times higher for $\mathrm{C}_{2} \mathrm{H}_{2}+\mathrm{SiHF}$ compared to $\mathrm{C}_{2} \mathrm{H}_{2}+\mathrm{SiF}$. Fig. 10 plots the calculated $\mathrm{C} / \mathrm{Si}$ impingement ratios for $\mathrm{SiF}$ and $\mathrm{SiHF}$ in combination with $\mathrm{C}_{2} \mathrm{H}_{2}$ for different inlet $\mathrm{Si} / \mathrm{H}_{2}$ and inlet $\mathrm{C} / \mathrm{Si}$ ratios.
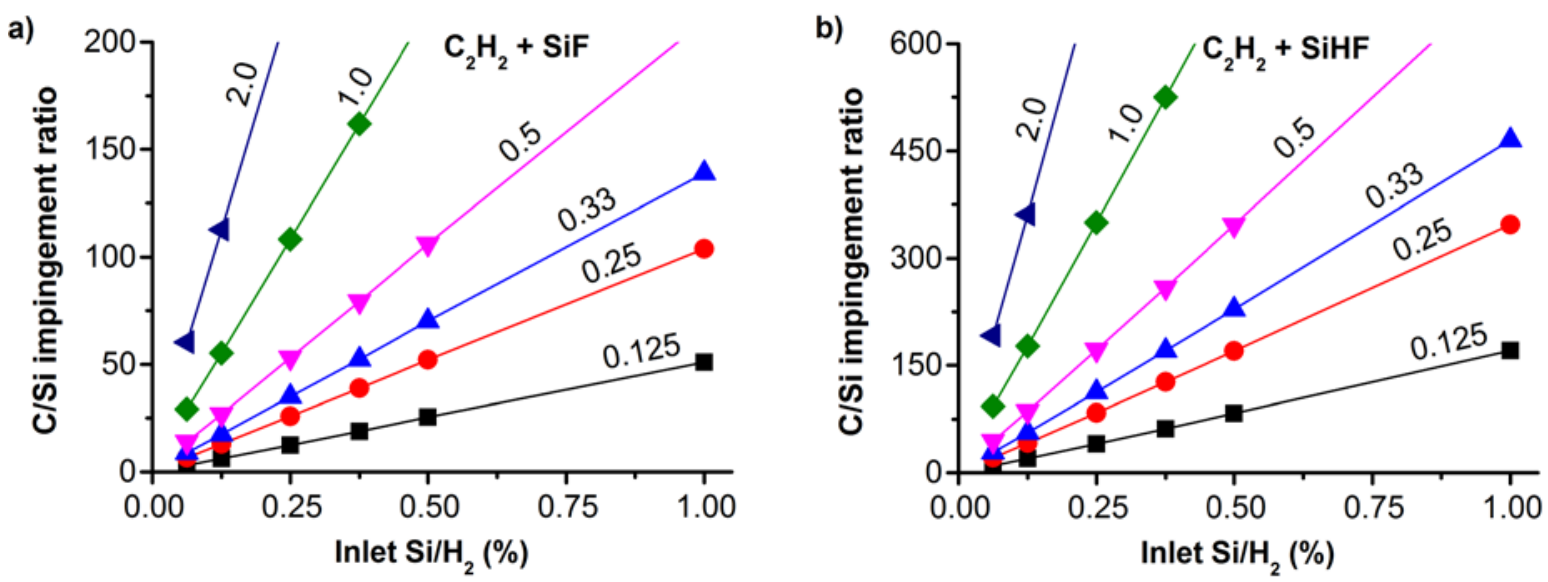

Figure 10. C/Si impingement ratio calculated by thermal equilibrium calculations at $\mathrm{T}=1600{ }^{\circ} \mathrm{C}$ for the species combinations a) $\mathrm{C}_{2} \mathrm{H}_{2}+\mathrm{SiF}$ and b) $\mathrm{C}_{2} \mathrm{H}_{2}+\mathrm{SiHF}$. The labels next to the lines indicate the inlet C/Si ratio. The calculations show that the $\mathrm{C} / \mathrm{Si}$ impingement ratio increases with increased inlet $\mathrm{Si} / \mathrm{H}_{2}$ ratio, even though the inlet C/Si is constant. Lines are guidance for the eye. The scales for the C/Si impingement ratio are cut at 200 and 600 , respectively. 
To correlate the calculated C/Si impingement ratios to the positions of the onset of epitaxial growth (Fig. 4), Fig. 11 shows the positions of the onset of epitaxial growth superimposed on an interpolated color representation of the calculated C/Si impingement ratios.
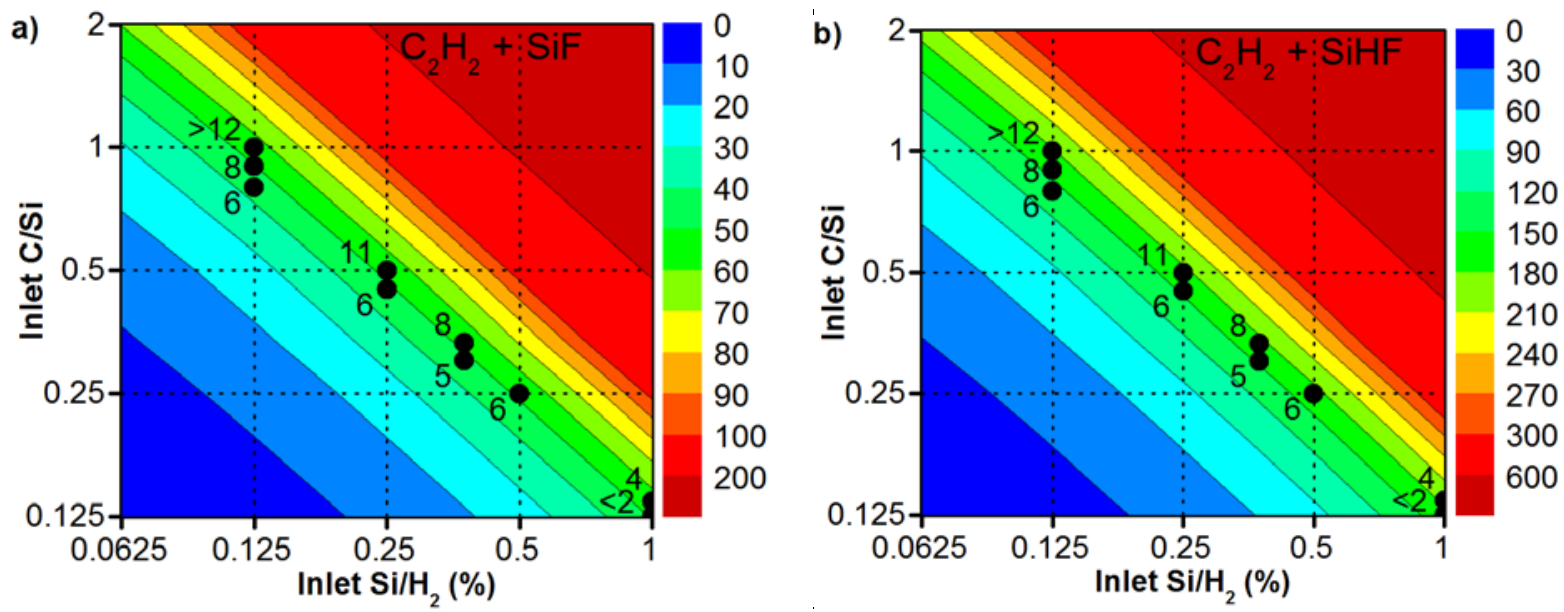

Figure 11. The positions of the onset of epitaxial growth from experiments and the C/Si impingement ratio from thermal equilibrium calculations at $\mathrm{T}=1600{ }^{\circ} \mathrm{C}$ for the species combinations a) $\mathrm{C}_{2} \mathrm{H}_{2}+\mathrm{SiF}$ and b) $\mathrm{C}_{2} \mathrm{H}_{2}+\mathrm{SiHF}$. Note the different color scales.

Both species combinations show an agreement between the $\mathrm{C} / \mathrm{Si}$ impingement ratio and position for the onset of epitaxial growth for different experimental parameters. When the C/Si impingement ratio becomes low enough, the growth of $\mathrm{SiC}$ is epitaxial. This observation is supported by the classical CVD structure/property/process relationship described by Blocher $^{26}$ where a low precursor concentration and a high temperature is deemed necessary for epitaxial growth.

To understand why the position of the onset of epitaxial growth is changed when the inlet $\mathrm{C} / \mathrm{H}_{2}$ is varied we recall the temperature dependence of the Si and $\mathrm{C}$ growth species around the growth process temperature. The impingement of $\mathrm{C}_{2} \mathrm{H}_{2}$ is almost constant from $1400{ }^{\circ} \mathrm{C}$ and upwards, while the Si growth species increase their impingement with increased temperature, decreasing the $\mathrm{C} / \mathrm{Si}$ impingement ratio as the temperature increases. The changed position of the onset of epitaxial 
growth with changed inlet $\mathrm{C} / \mathrm{H}_{2}$ ratio (or inlet $\mathrm{C} / \mathrm{Si}$ ratio for a specific inlet $\mathrm{Si} / \mathrm{H}_{2}$ ratio) is likely an effect of slow kinetics of the $\mathrm{SiF}_{4}$ precursor molecule to form Si growth species compared to the formation of C-species from $\mathrm{C}_{2} \mathrm{H}_{4}$ together with the temperature gradient in the susceptor (i.e. cooler at the inlet and hotter further downstream) and the gas mixture (i.e. cooler at the inlet as well as towards the middle of the gas flow and hotter further downstream as well as closer to surfaces). Here it should be emphasized that the reactor is designed in such way that susceptor in plane temperature gradients are minimized by designing inlet, front- and rear insulation to have steep temperature gradients. The heating of the gas inside the susceptor is compensated by thermal radiation at the rear of the susceptor. The susceptor temperature is therefore constant compared to the increasing temperature of the gas providing more growth species. This results in a steadily decreasing $\mathrm{C} / \mathrm{Si}$ impingement ratio by the increasing amount of $\mathrm{Si}$ growth species. If the ratio decreases enough, below the threshold limit, there will be epitaxial growth, and thereby an onset of epitaxial growth.

Reactivities of SiF, SiHF and $\mathrm{SiF}_{2}$ were studied via the adsorption processes modelled by the quantum chemical methods. The species were assumed to react with two types of surface carbon groups: first a $\mathrm{C}$ site without a dangling bond and then a $\mathrm{C}$ site including a dangling bond. These two cases were represented respectively by a methyl $\left(-\mathrm{CH}_{3}\right)$ and a methylene $\left(-\mathrm{CH}_{2}\right)$ group which have been pre-attached to the surface Si atom prior to the adsorption. Based on this scenario, we obtained the Gibbs free energies of adsorption and activation (if a saddle point exists).

It is observed that the Gibbs free energies of adsorption increase monotonically with the rise of the process temperature. The relations between the process temperature and the Gibbs free energies of adsorption over 400 to $2200{ }^{\circ} \mathrm{C}$ are shown in Fig. 12a-b. At room temperature the adsorptions starts with negative values for all cases but then changes signs when the temperature reaches the 
following values: $1763^{\circ} \mathrm{C}, 1023^{\circ} \mathrm{C}$ and $613^{\circ} \mathrm{C}$ for the $\mathrm{SiF}, \mathrm{SiHF}$ and $\mathrm{SiF} 2$ on a methylene site and $504{ }^{\circ} \mathrm{C}, 850{ }^{\circ} \mathrm{C}$ and $524{ }^{\circ} \mathrm{C}$ for $\mathrm{SiF}, \mathrm{SiHF}$ and $\mathrm{SiF}_{2}$ on a methyl site. This means that approaching the growth temperature, the Gibbs energies have all become positive for the adsorptions on a methyl site as well as the adsorptions of $\mathrm{SiHF}$ and $\mathrm{SiF}_{2}$ on a methylene site. The only exception is the $\mathrm{SiF}$ adsorption on a methylene site, at least when the temperature is less than $1763{ }^{\circ} \mathrm{C}$.
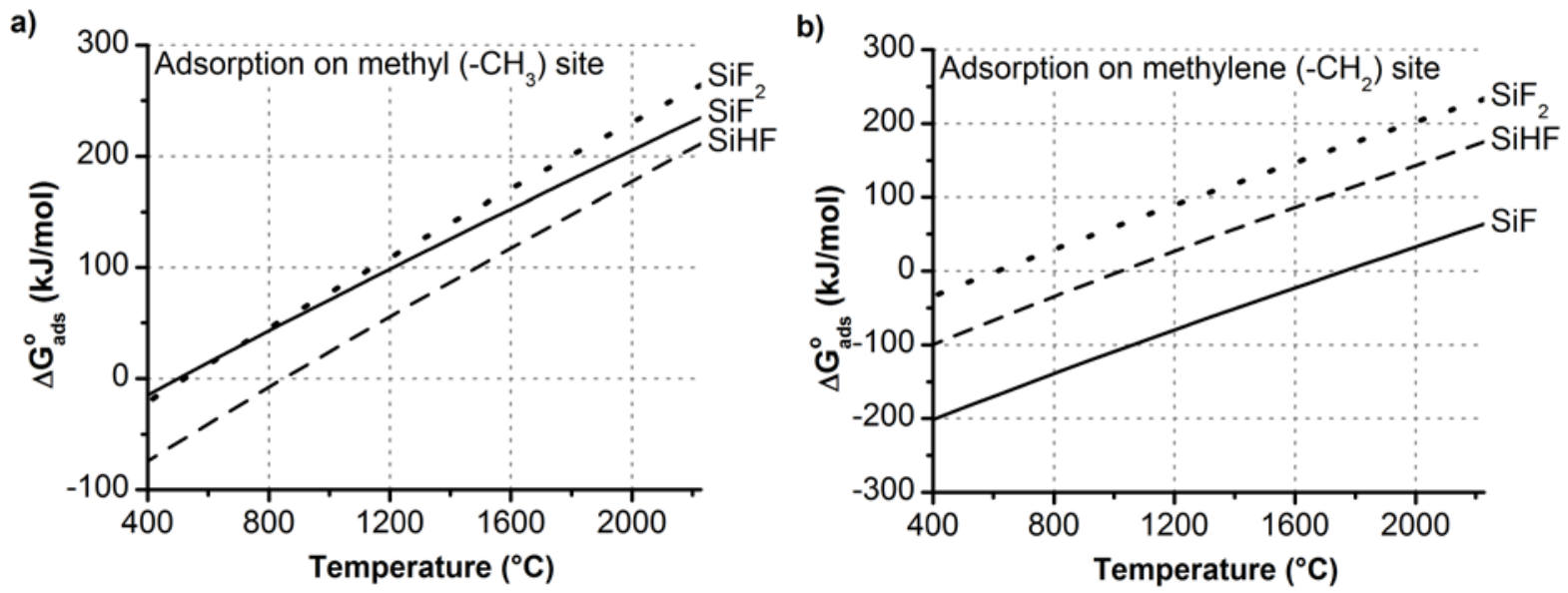

Figure 12. Relations between the temperature and the Gibbs free energies of adsorption $\left(\Delta \mathrm{G}^{\circ}\right.$ ads $)$ of the $\mathrm{SiF}$ (solid), SiHF (dash) and $\mathrm{SiF}_{2}$ (dot) on a) a methyl $\left(-\mathrm{CH}_{3}\right)$ site and b) a methylene $\left(-\mathrm{CH}_{2}\right)$ site. The Gibbs free energies as functions of temperature were derived using density functional theory as described in the methods, surface chemistry modelling subsection.

The positive Gibbs energies calculated for the surface reactions suggest that the adsorptions are thermodynamically unfavorable in comparison to the reverse, namely surface desorptions via the same pathway. However, a positive $\Delta \mathrm{G}^{\circ}$ simply implies that the numerical value of the equilibrium constant is below one, i.e. the reaction is shifted to the left. We can see that SiF has the largest equilibrium constant followed by $\mathrm{SiHF}$ and then by $\mathrm{SiF}_{2}$ for adsorption on methylene, and that the equilibrium constant is even larger than one (negative $\Delta \mathrm{G}^{\circ}$ ) for $\mathrm{SiF}$, at typical growth temperatures. It is worth noting that the presence of a dangling bond residing at the methylene group, $\mathrm{CH}_{2}$ (ads) 
on the surface helps lowering the Gibbs energies of adsorptions. The most significant reduction is in the $\mathrm{SiF}$ adsorption on methylene which is a radical-radical reaction.

With the Gibbs free energies of adsorption we arrive at the prediction of how likely the process may occur. To explicitly determine the reaction rates or the sticking coefficients would invoke the knowledge of both the Gibbs energies of adsorption as well as the potential energy surface along the reaction coordinates. For the adsorptions on a methyl site, there exists a saddle point between the reactant and the product states for which the Gibbs free energies of activation over the range of 400 to $2200{ }^{\circ} \mathrm{C}$ is shown in Fig. 13.

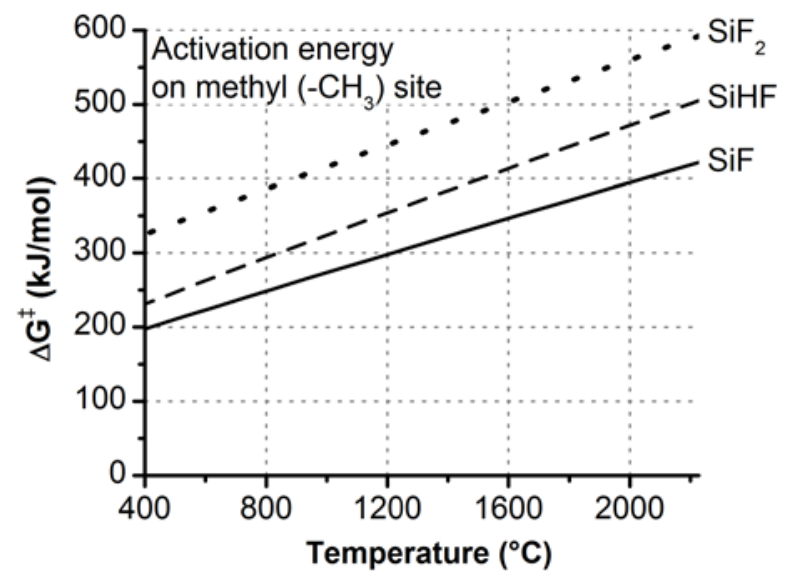

Figure 13. Relations between the temperature and the Gibbs free energies of activation $\left(\Delta \mathrm{G}^{\ddagger}\right)$ of the $\operatorname{SiF}$ (solid), $\mathrm{SiHF}$ (dash) and $\mathrm{SiF}_{2}$ (dot) on a methyl $\left(-\mathrm{CH}_{3}\right)$ site. The Gibbs free energies as functions of temperature were derived using density functional theory as described in the methods, surface chemistry modelling subsection.

At $1600{ }^{\circ} \mathrm{C}$ these barrier heights become relatively high in energy in comparison to the reactant ground state as depicted in Fig. 14a. Using transition state theory we extracted the sticking coefficients at $1600{ }^{\circ} \mathrm{C}$ to be $\sim 7.4 \cdot 10^{-5}$ for $\mathrm{SiF}, \sim 1.0 \cdot 10^{-6}$ for SiHF and $\sim 3.3 \cdot 10^{-9}$ for $\mathrm{SiF}_{2}$. The barriers of desorption via the same pathway are smallest in SiF (194 kJ/mol), followed by SiHF 
(296 kJ/mol) and $\mathrm{SiF}_{2}(333 \mathrm{~kJ} / \mathrm{mol})$. Hence, it is easier for the adsorbed SiF to desorb back into gas phase than for the adsorbed $\mathrm{SiHF}$ or $\mathrm{SiF}_{2}$ species. Adsorptions on a methylene site do not occur with saddle points between the reactants and products as presented in Fig. 14b. It is therefore not suitable to use conventional transition state theory to derive the rate constants or sticking coefficients for adsorption process on a methylene. Nevertheless, we expect all sticking coefficients to be relatively large. As shown in Fig. 14b, adsorption of SiF occurs with negative Gibbs free energies at $1600{ }^{\circ} \mathrm{C}$, in contrast to $\mathrm{SiHF}$ and $\mathrm{SiF}_{2}$. This suggests that for $\mathrm{SiF}$ the process of adsorption is preferable over desorption via the same pathway. Hence, among these three species $\mathrm{SiF}$ is likely the most active growth contributor. Unlike $\mathrm{SiF}$, both $\mathrm{SiHF}$ and $\mathrm{SiF}_{2}$ prefer the process of desorption to adsorption. The larger positive Gibbs free energy of adsorption suggests that desorption is more favorable for $\mathrm{SiF}_{2}$ than for SiHF. Hence, SiHF will likely contribute to growth more effectively than $\mathrm{SiF}_{2}$. From these facts it is clear that $\mathrm{SiF}_{2}$ is much less likely to contribute to the growth than SiF and SiHF. This could also be viewed as support for a suggested etching mechanism where $\mathrm{SiF}_{4}$ etches away $\mathrm{Si}$ by forming two $\mathrm{SiF}_{2}$, which leave the surface. ${ }^{27}$ This coincides with the experimental results between the onset of epitaxial growth and the $\mathrm{C} / \mathrm{Si}$ impingement ratio. 
a)

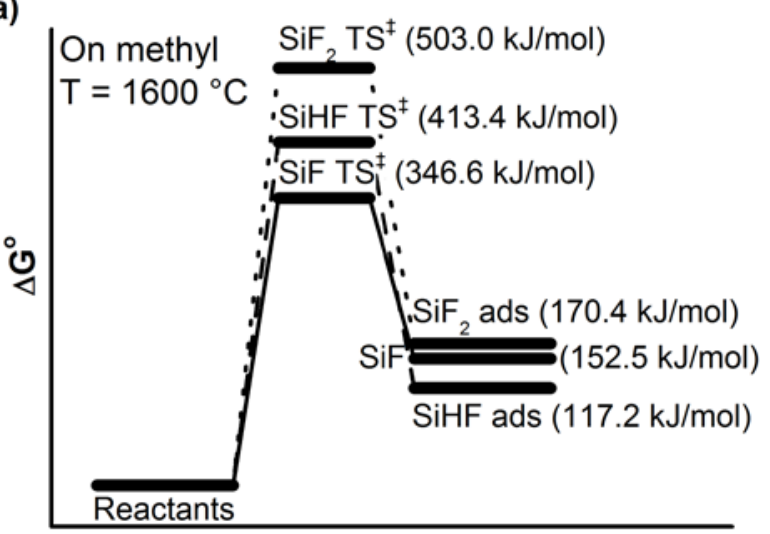

Reaction Coordinate

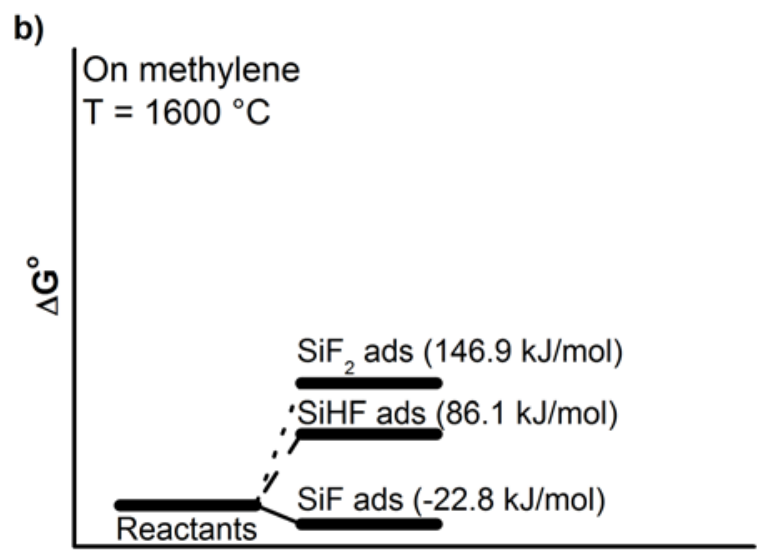

Reaction Coordinate

Figure 14. Gibbs free energies of activation and adsorption at $\mathrm{T}=1600{ }^{\circ} \mathrm{C}$ of the $\mathrm{SiF}(\mathrm{g}), \operatorname{SiHF}(\mathrm{g})$ and $\mathrm{SiF}_{2}(\mathrm{~g})$ on a) a methyl $\left(-\mathrm{CH}_{3}\right)$ site and b) a methylene $\left(-\mathrm{CH}_{2}\right)$ site. The Gibbs free energies as functions of temperature were derived using density functional theory as described in the methods, surface chemistry modelling subsection.

In general, the results from the quantum chemical modeling show that it is unlikely for the Sispecies to get adsorbed on a fully bonded carbon site located on a smooth H-terminated Si terrace. However, when a dangling bond is introduced on the carbon site, adsorption of SiF species become thermodynamically favorable. Even though adsorptions of $\mathrm{SiHF}$ and $\mathrm{SiF}_{2}$ on $\mathrm{CH}_{2}$ (ads) occur with positive Gibbs free energies, we believe that the system can be stabilized even further by subsequently bonding the Si group to another adjacent $\mathrm{C}$ group. If this is the case, then adsorption at steps will definitely have advantages over terraces since adjacent $C$ groups are available at step while it is not always the case for terraces. The non-epitaxial growth upstream of the onset of epitaxial growth could be a result of a $\sim 100 \% \mathrm{CH}_{3}$ terminated surface from the high $\mathrm{C} / \mathrm{Si}$ impingement ratio. The triangular surface defects can then be a result of growth at steps under carbon rich conditions, although this is only speculations, which require a more thorough investigation. 


\section{Conclusion}

By using a combination of growth experiments, thermochemical and quantum chemical modeling we can now present a better understanding of the CVD chemistry for CVD of $\mathrm{SiC}$ using $\mathrm{SiF}_{4}$ as $\mathrm{Si}$ precursor. The experiments use the onset of epitaxial growth as the observable for how the $\mathrm{C} / \mathrm{Si}$ ratio of the impinging species. The difference in C and Si chemistry in the fluorinated chemistry makes the $\mathrm{C} / \mathrm{Si}$ impingement ratio strongly dependent on the temperature and precursor concentrations. It is observed that a process generating a high C/Si impingement ratio hinders the growth of $\mathrm{SiC}$. When the $\mathrm{C} / \mathrm{Si}$ impingement ratio is low enough, the growth of $\mathrm{SiC}$ is epitaxial.

Thermochemical calculations shows that the possible $\mathrm{Si}$ bearing species for growth are $\mathrm{SiF}_{2}, \mathrm{SiF}$ and SiHF. By modeling the observed changes in onset of epitaxial growth we conclude that $\mathrm{SiF}$ is the main $\mathrm{Si}$ bearing species for $\mathrm{SiC}$ growth with minor contribution from $\mathrm{SiHF}$. $\mathrm{SiF}_{2}$ is concluded not to contribute to the $\mathrm{SiC}$ growth. This conclusion is further supported by quantum chemical modeling where SiF is the only Si species with a favorable adsorption Gibbs free energy.

\section{Acknowledgement}

This work was supported by the Knut \& Alice Wallenberg Foundation (KAW) project "Isotopic Control for Ultimate Material Properties", Swedish Foundation for Strategic Research project "SiC - the Material for Energy-Saving Power Electronics" (EM11-0034) and the Advanced Functional Materials (AFM) at Linköping University. Supercomputing resources were provided by the Swedish National Infrastructure for Computing (SNIC) and the Swedish National Supercomputer Centre (NSC). 


\section{Supporting Information}

Further details on the onset of growth, quantum-chemical calculations with a larger SiC cluster, derivation of the impingement rate needed for a certain growth rate, impingement rates of other $\mathrm{C}$ and Si species and safety precautions for working with the risk of residual HF vapors from a CVD process with $\mathrm{SiF}_{4}$ are available free of charge via the Internet at http://pubs.acs.org.

\section{References}

(1) Cooper, J. A.; Agarwal, A. SiC power-switching devices-the second electronics revolution? Proc. IEEE 2002, 90, 956-968.

(2) Weitzel, C. E.; Palmour, J. W.; Carter, C. H.; Moore, K.; Nordquist, K. J.; Alien, S.; Thero, C.; Bhatnagar, M. Silicon carbide high power devices. IEEE Trans. Electron Devices 1996, 43, 1732-1741.

(3) Crippa, D.; Valente, G. L.; Ruggiero, A.; Neri, L.; Reitano, R.; Calcagno, L.; Foti, G.; Mauceri, M.; Leone, S.; Pistone, G. et al. New achievements on CVD based methods for SiC epitaxial growth. Mater. Sci. Forum 2005, 483-485, 67-72.

(4) "Bond Dissociation Energies," in CRC Handbook of Chemistry and Physics (Internet Version 2017) (W. M. Haynes, ed.), ch. 9, pp. 73-102, CRC Press/Taylor \& Francis, Boca Raton, FL, 97 ed., 2017.

(5) Pedersen, H.; Leone, S.; Kordina, O.; Henry, A.; Nishizawa, S. I.; Koshka Y.; Janzén, E. Chloride-based CVD growth of silicon carbide for electronic applications. Chem. Rev. 2012, 112, 2434-2453.

(6) Yazdanfar, M.; Danielsson, Ö.; Kalered, E.; Sukkaew, P.; Kordina, O.; Nilsson, D.; Ivanov, I. G.; Ojamäe, L.; Janzén, E. Pedersen, H. Brominated chemistry for chemical vapor deposition of electronic grade SiC. Chem. Mater. 2015, 27, 793-801.

(7) Rana, T.; Chandrashekhar M. V. S.; Sudarshan, T. S. Elimination of silicon gas phase nucleation using tetrafluorosilane $\left(\mathrm{SiF}_{4}\right)$ precursor for high quality thick silicon carbide (SiC) homoepitaxy. Phys. Status Solidi A 2012, 209, 2455-2462. 
(8) See the electronic Supporting Information

(9) Musket, R. G.; Yoshiyama, J. M.; Contolini, R. J.; Porter, J. D. Vapor etching of ion tracks in fused silica. J. Appl. Phys. 2002, 91, 5760-5764.

(10) Habuka, H.; Otsuka, T. Reaction of hydrogen fluoride gas at high temperatures with silicon oxide film and silicon surface, Jpn. J. Appl. Phys., 1998, 37, 6123-6127.

(11) Allendorf, M. D.; Melius, C. F. Theoretical study of the thermochemistry of molecules in the silicon-carbon-hydrogen system. J. Phys. Chem. 1992, 96, 428-437.

(12) Deng, J. L.; Su, K. H.; Wang, X.; Zeng, Q. F.; Cheng, L. F.; Xu Y. D.; Zhang, L. T. Thermodynamic properties of the most stable gaseous small silicon-carbon clusters in their ground states. Eur. Phys. J. D 2008, 49, 21-35.

(13) Sukkaew, P.; Ojamäe, L.; Kordina, O.; Janzén, E.; Danielsson, Ö. Thermochemical properties of halides and halohydrides of silicon and carbon. ECS J. Solid State Sci. Technol. 2016, 5, 27-35.

(14) Frisch, M. J.; Trucks, G. W.; Schlegel, H. B.; Scuseria, G. E.; Robb, M. A.; Cheeseman, J. R.; Scalmani, G.; Barone, V.; Mennucci, B.; Petersson, G. A. et al. Gaussian 09, Gaussian, Inc.: Wallingford, CT, 2009.

(15) Becke, A. D. Density-functional thermochemistry. III. The role of exact exchange. $J$. Chem. Phys. 1993, 98, 5648-5652.

(16) Lee, C.; Yang, W.; Parr, R. G. Development of the Colle-Salvetti correlation-energy formula into a functional of the electron density. Phys. Rev. B, 1988, 37, 785-789.

(17) Dunning, T. H.; Hay, P. J. in Methods of Electronic Structure Theory, ed. H. F. Schaefer, Springer US, Boston, MA, 1977, pp. 1-27.

(18) Wadt, W. R.; Hay, P. J. Ab initio effective core potentials for molecular calculations. Potentials for main group elements Na to Bi. J. Chem. Phys. 1985, 82, 284-298.

(19) Grimme, S.; Antony, J.; Ehrlich, S.; Krieg, H. A consistent and accurate ab initio parametrization of density functional dispersion correction (DFT-D) for the 94 elements H-Pu. J. Chem. Phys. 2010, 132, 154104.

(20) Zhao, Y.; Truhlar, D. G. The M06 suite of density functionals for main group thermochemistry, thermochemical kinetics, noncovalent interactions, excited states, and transition elements: two new functionals and systematic testing of four M06-class functionals and 12 other functionals. Theor. Chem. Acc. 2008, 120, 215-241.

(21) Curtiss, L. A.; Redfern, P. C.; Raghavachari, K. Gaussian-4 theory. J. Chem. Phys. 2007, 126, 084108.

(22) Leone, S.; Henry, A.; Andersson, S.; Kordina, O.; Janzén, E. Optimization of a concentrated chloride-based CVD process for $4 \mathrm{H}-\mathrm{SiC}$ epilayers. J. Electrochem. Soc. 2010, 157, H969-H976.

(23) Henry, A.; Leone, S.; Beyer, F. C.; Pedersen, H.; Kordina, O.; Andersson S.; Janzén, E. SiC epitaxy growth using chloride-based CVD. Phys. B Condens. Matter 2012, 407, 14671471. 
(24) Yazdanfar, M.; Stenberg, P.; Booker, I. D.; Ivanov, I. G.; Kordina, O.; Pedersen, H.; Janzén, E. Process stability and morphology optimization of very thick 4H-SiC epitaxial layers grown by chloride-based CVD. J. Cryst. Growth 2013, 380, 55-60.

(25) Balachandran, A.; Song, H.; Sudarshan, T. S.; Chandrashekhar, M. V. S. 4H-SiC homoepitaxy on nearly on-axis substrates using TFS-towards high quality epitaxial growth. J. Cryst. Growth 2016, 448, 97-104.

(26) Blocher, J. M. Structure/property/process relationships in chemical vapor deposition CVD. J. Vac. Sci. Technol. 1974, 11, 680-686.

(27) Rana, T.; Chandrashekhar, M. V. S.; Sudarshan, T. S. Vapor phase surface preparation (etching) of $4 \mathrm{H}-\mathrm{SiC}$ substrates using tetra fluorosilane $\left(\mathrm{SiF}_{4}\right)$ in a hydrogen ambient for SiC epitaxy. J. Cryst. Growth, 2013, 380, 61-67.

\section{TOC image}

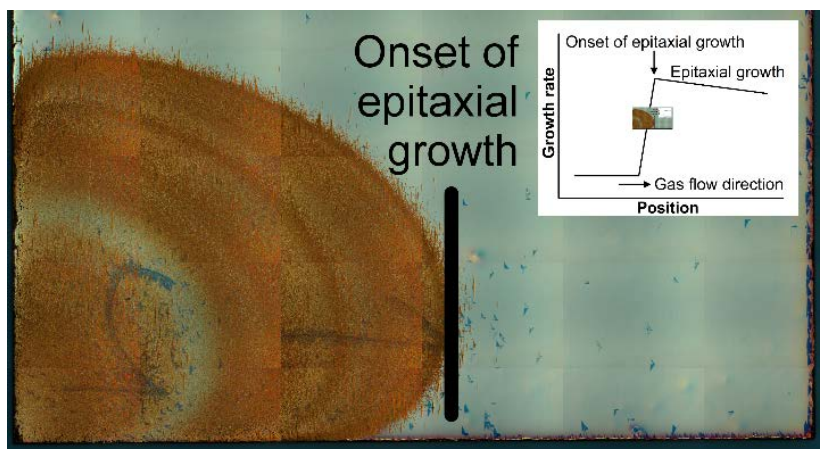




\title{
Supporting Information for
}

\section{Silicon Chemistry in Fluorinated Chemical Vapor Deposition of Silicon Carbide}

\author{
Pontus Stenberg, Pitsiri Sukkaew, Ildiko Farkas, Olof Kordina, Erik Janzén, \\ Lars Ojamäe, Örjan Danielsson, Henrik Pedersen*
}

Department of Physics, Chemistry and Biology, Linköping University, 58183 Linköping, Sweden

* henrik.pedersen@liu.se

\section{Cluster model.}

The $\mathrm{Si}_{13} \mathrm{C}_{13} \mathrm{H}_{32}$ cluster has been tested against a larger cluster, $\mathrm{Si}_{22} \mathrm{C}_{22} \mathrm{H}_{44}$, for adsorption process of gaseous $\mathrm{SiF}$, $\mathrm{SiHF}$ and $\mathrm{SiF}_{2}$ on a methyl group. The Gibbs free energies of reaction $\left(\Delta_{\mathrm{R}} \mathrm{G}^{\circ}\right)$ and of activation $\left(\Delta \mathrm{G}^{\ddagger}\right)$ were calculated and compared as shown in Table S1 below.

\begin{tabular}{|c|r|r|r|r|r|r|r|r|}
\hline & \multicolumn{4}{|c|}{$\mathrm{Si}_{13} \mathrm{C}_{13} \mathrm{H}_{32}$} & \multicolumn{4}{c|}{$\mathrm{Si}_{22} \mathrm{C}_{22} \mathrm{H}_{44}$} \\
\cline { 2 - 10 }$\Delta_{\mathbf{R}} \mathbf{G}^{\circ}$ & $400{ }^{\circ} \mathrm{C}$ & $1000^{\circ} \mathrm{C}$ & $1600{ }^{\circ} \mathrm{C}$ & $2200{ }^{\circ} \mathrm{C}$ & $400{ }^{\circ} \mathrm{C}$ & $1000{ }^{\circ} \mathrm{C}$ & $1600{ }^{\circ} \mathrm{C}$ & $2200{ }^{\circ} \mathrm{C}$ \\
\hline SiF adsorption & -15 & 71 & 152 & 231 & -15 & 70 & 150 & 228 \\
\hline SiHF adsorption & -74 & 24 & 117 & 207 & -74 & 24 & 118 & 208 \\
\hline $\mathrm{SiF}_{2}$ adsorption & -21 & 78 & 170 & 260 & -19 & 78 & 170 & 258 \\
\hline$\Delta \mathbf{G}^{\ddagger}$ & & & & & & & & \\
\hline SiF adsorption & 197 & 273 & 347 & 419 & 192 & 268 & 341 & 413 \\
\hline SiHF adsorption & 231 & 324 & 413 & 501 & 232 & 325 & 416 & 504 \\
\hline SiF 2 adsorption & 325 & 416 & 503 & 588 & 326 & 420 & 510 & 598 \\
\hline
\end{tabular}

Table S1. The Gibbs free energies derived using the $\mathrm{Si}_{13} \mathrm{C}_{13} \mathrm{H}_{32}$ cluster in comparison to the results calculated from a larger cluster, $\mathrm{Si}_{22} \mathrm{C}_{22} \mathrm{H}_{44}$. Here, $\Delta_{\mathrm{R}} \mathrm{G}^{\circ}$ and $\Delta \mathrm{G}^{\ddagger}$ refer to the Gibbs free energies of reaction and of activation, respectively. The results are shown for adsorption process of gaseous $\mathrm{SiF}, \mathrm{SiHF}$ and $\mathrm{SiF}_{2}$ on a methyl group $\left(-\mathrm{CH}_{3}\right)$. The Gibbs free energies are shown in $\mathrm{kJ} / \mathrm{mol}$ unit. 


\section{Surface chemistry modelling.}

Based on a simplified work of Reuter and Scheffler's ${ }^{1}$, the adsorption rate $\left(R_{a d s}\right)$ can be written as

$$
R_{a d s}=\Phi \cdot \Theta \cdot A_{s} f_{a d s} \exp \left(-\Delta E_{a d s} / k_{B} T\right)
$$

where

$$
f_{a d s}=\mathrm{q}_{\text {vib,el }}^{T S} /\left(\mathrm{q}_{2 D-\text { Trans }}^{\text {gas }} \cdot \mathrm{q}_{\text {int }}^{\text {gas }} \mathrm{q}_{\text {vib,el }}^{\text {surf }}\right)
$$

and

$$
\Phi=\gamma_{A} p / \sqrt{2 \pi m_{A} k_{B} T}
$$

Here $\Phi$ is the molecular impingement flux in the unit of molecule area ${ }^{-1}$ time $^{-1}$ where $\gamma_{A}, p, m_{A}$, $k_{B}$ and $T$ are respectively the molar fraction of the adsorbing molecule A in gas phase, the total pressure, the mass of molecule A, the Boltzmann constant, and temperature in Kelvin. $\Theta$ is the surface fraction of the adsorption sites. $A_{s}$ is the area per site.

$f_{a d s}$ contains the contributions from the partition functions (q). The partition functions related to the surface (i.e. those of the transition state $\left(\mathrm{q}_{v i b, e l}^{T S}\right)$ and the surface $\left.\left(\mathrm{q}_{v i b, e l}^{\text {surf }}\right)\right)$ include only the vibrational and electronic parts, while for the gases, all parts are included except translation along the reaction coordinates. The translational part of the gas partition function is written separately as $\mathrm{q}_{2 D-\text { Trans }}^{\text {gas }}$, to highlight the fact that only 2 out of 3 dimensions are included, while the vibrational, rotational and electronic parts are included together in the term $\mathrm{q}_{\text {int }}^{\text {gas }}$. Lastly $\Delta E_{a d s}$ is the adsorption barrier at $0 \mathrm{~K}$ with the zero point correction energy included.

From the adsorption rate and the impingement flux, we can then define the sticking coefficient $\left(S_{A}\right)$ by $S_{A}=R_{a d s} / \Phi \cdot \Theta$. Hence we obtain

$$
S_{A}=f_{a d s} \exp \left(-\Delta E_{a d s} / k_{B} T\right)
$$




\section{Adsorption rate to achieve $\sim 10 \mu \mathrm{m} / \mathrm{h}$.}

Adsorption rate, $\Phi$, is the number of hits per unit second per unit area. That can be formulated as

$$
\Phi=v / A
$$

where $v$ is the hit rate $(1 / \mathrm{s})$ and A the area $\left(\mathrm{m}^{2}\right)$.

To achieve a growth rate of $10 \mu \mathrm{m} / \mathrm{h}$ we first recall that the height of the $4 \mathrm{H}$-SiC unit cell is $\mathrm{c}=1.0053 \cdot 10^{-9} \mathrm{~m}$ gives the distance between two bilayers; $2.5131 \cdot 10^{-10} \mathrm{~m}$. That gives us the growth rate as

$$
10 \mu \mathrm{m} / \mathrm{h}=10 \cdot 10^{-6} \mathrm{~m} / \mathrm{h}=3.979 \cdot 10^{4} \text { bilayers } / \mathrm{h}=11.05 \text { bilayers } / \mathrm{s} \text { (Eq. S6) }
$$

Therefore, for the area A of a surface site the hit rate

$$
v=11.05 / s
$$

The area for a surface site in the hcp structure for $4 \mathrm{H}-\mathrm{SiC}$ in the c-plane to which $v$ applies is 3 sites per hexagon with side lengths $a$, which gives the area of 1 site as 2 triangles with side lengths $a$

$$
A=2 \cdot \frac{1}{2} \cdot a^{2} \cdot \sin 60^{\circ}=2 \cdot \frac{1}{4} \cdot \sqrt{3} \cdot\left(3.0730 \cdot 10^{-10} \mathrm{~m}\right)^{2}=8.178 \cdot 10^{-20} \mathrm{~m}^{2}
$$

where $a$ is the in plane lattice constant. That gives the needed adsorption rate

$$
\begin{gathered}
\Phi=v / A=(11.05 / \mathrm{s}) /\left(8.178 \cdot 10^{-20} \mathrm{~m}^{2}\right)=1.351 \cdot 10^{20} / \mathrm{m}^{2} / \mathrm{s}= \\
=2.2 \cdot 10^{-4} \mathrm{~mol} / \mathrm{m}^{2} / \mathrm{s}
\end{gathered}
$$




\section{$\mathrm{C} / \mathrm{Si}$ impingement rate for other species combinations.}

For a comparison to what the $\mathrm{C} / \mathrm{Si}$ impingement ratio would have looked like with $\mathrm{SiF}_{2}$ being the Si growth species, Fig S1 shows the behavior together with the growth onset positions. The correlation between the $\mathrm{C} / \mathrm{Si}$ impingent ratio and the position for the onset of epitaxial growth is week.

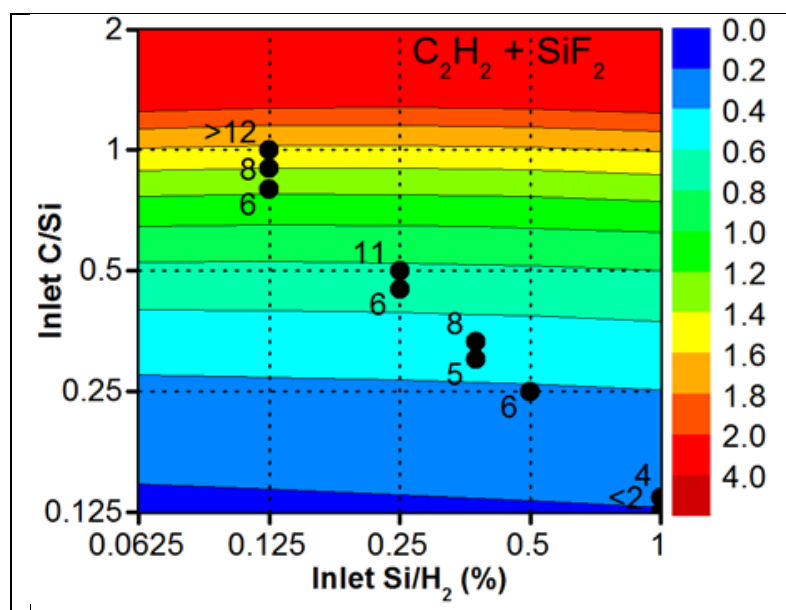

Figure S1. The growth onset position from experiments and the C/Si impingement ratio from thermal equilibrium calculations at $\mathrm{T}=1600{ }^{\circ} \mathrm{C}$ for the species combination $\mathrm{C}_{2} \mathrm{H}_{2}+\mathrm{SiF}_{2}$. The weak correlation between the $\mathrm{C} / \mathrm{Si}$ impingement ratio and the onset of epitaxial growth indicate that $\mathrm{SiF}_{2}$ is not the main $\mathrm{Si}$ growth species.

\section{Security precautions regarding HF as a byproduct from the process.}

As $\mathrm{SiF}_{4}$ is used together with hydrogen, the formation of hydrogen fluoride (HF) is inevitable. Traces of HF bound in the parasitic deposition downstream of the susceptor can evaporate into the air and form HF (aq) upon reacting with the moisture in the air. To avoid that personnel get exposed to HF when opening the CVD reactor, a point exhaust at the loading flange is found to prevent most HF from spreading to the surroundings. A handhold detector is used to monitor the concentration of HF in the air. Concentrations higher than $0.3 \mathrm{ppm}$ can be detected, which is below NIOSH time weight averaged Recommended Exposure Limits of 3 ppm for a 10 hour exposure. ${ }^{2}$ 
No detectable concentrations of $\mathrm{HF}(<0.3 \mathrm{ppm})$ is found when the point exhaust is placed at the pump line downstream of the flange, which cannot be cleaned in run-to-run cleaning. This indicates that the HF is released from parasitic deposition, especially when the parasitic deposition has built up during a long time, and that no HF is released from the graphite parts in the hot zone. To further protect personnel, gas mask and gloves with 5 minutes breakthrough time for $48 \% \mathrm{HF}(\mathrm{aq})$ are used during the cleaning of the cell. When parts with parasitic deposition were cleaned using ethanol, HF was normally released, which could be detected when the hand hold detector was placed close to the part being cleaned. If the parts had been exposed to air for circa one minute, no detectable HF was released upon cleaning with ethanol.

\section{References}

1 Reuter, K.; Scheffler, M. First-principles kinetic Monte Carlo simulations for heterogeneous catalysis: Application to the $\mathrm{CO}$ oxidation at $\mathrm{RuO}_{2}(110)$. Phys. Rev. B, 2006, 73, 45433.

2 http://www.cdc.gov/niosh/ershdb/emergencyresponsecard_29750030.html, 2015. 